\title{
JUSTICIA CIVIL: DIAGNÓSTICO, EVIDENCIA EMPÍRICA Y LINEAMIENTOS PARA UNA REFORMA
}

\author{
José Francisco García* \\ Francisco Javier Leturia ${ }^{* *}$
}

\begin{abstract}
RESUMEN: Los autores proponen los elementos centrales que deben considerarse en el diseño de una Reforma a la Justicia Civil en Chile, la cual no puede ser puramente procedimiental, sino que debe fundarse en una profunda transformación del actual sistema. Serán cuestiones de mayor relevancia en esta reforma las referidas a la racionalización de funciones de los jueces; al fomento de las llamadas formas alternativas de resolución de conflictos; incentivos a la existencia de una jurisprudencia estable y coherente; a la profesionalización de la gestión administrativa de los tribunales (al igual que la disciplinaria), promoción de la transparencia y el accountability judicial; y al establecimiento de un sistema mixto de financiamiento de la nueva justicia.
\end{abstract}

Palabras clave: Justicia civil, tribunales civiles, reforma procesal, reforma judicial, análisis económico del derecho.

ABSTRACT: The authors propose the central elements that must be considered in the design of the Reformation to civil justice in Chile, which cannot be purely procedural, but that must mean one complete transformation of the present system. The referred ones to the restriction of functions of the judges will be questions of greater relevance in this reform; to the promotion of alternative forms of resolution of conflicts; incentives to the existence of a stable and coherent jurisprudence; to the specialization of the administrative management of the courts, the promotion of transparency and judicial accountability; and to the establishment of a mixed system of financing of the new justice.

Key words: Civil justice, civil courts, procedural reform, judicial reform, law \& economics.

\section{INTRODUCCIÓN}

En las últimas décadas, la Reforma Procesal Penal ha constituido el hito más relevante en materia de reforma a la justicia en Chile. Tanto es así, que existe la percepción de que este esfuerzo ha concentrado el dinamismo y la energía de los actores vinculados al sector justicia. No obstante los avances parciales en algunas áreas (laboral, familia) sigue pendiente una extensa agenda de reformas y modernizaciones en el sector, donde existe una percepción pública transversalmente concordante en cuanto a la baja calidad de la justicia. Desgraciadamente, ello tiene un impacto directo en la confianza de la sociedad hacia el sistema legal y hacia el funcionamiento institucional en general, lo que a su vez repercute en el ánimo y las conductas sociales. En este sentido, diversas

\footnotetext{
* Abogado. Profesor Pontificia Universidad Católica de Chile. LL.M y candidato a Doctor en Derecho, Universidad de Chicago. Investigador Libertad y Desarrollo.

** Abogado. Profesor Pontificia Universidad Católica de Chile.
} 
encuestas de opinión son consistentes en demostrar el progresivo deterioro de la confianza de los ciudadanos chilenos en el Poder Judicial, lo que a su vez puede tener impacto en la percepción de corrupción al interior de este ${ }^{1}$.

Lo anterior se ve amplificado por el distanciamiento y falta de conocimiento de la ciudadanía respecto de dicho poder, ya que se carece de información básica respecto de las actuaciones del mismo, dificultando la fiscalización ciudadana y la crítica propositiva seria. Aunque no es materia de este trabajo, queremos consignar que la falta de acceso a la información judicial en nuestro país es preocupante ${ }^{2}$.

En un escenario tan complejo es fundamental priorizar las áreas en que se debe iniciar o profundizar el proceso de reforma judicial. En materia de justicia civil, la dificultad de acceso, la demora y congestión de los procedimientos, y la poca utilización de los llamados mecanismos alternativos de resolución de conflictos, son factores que influyen negativamente en la forma como se están resolviendo los conflictos de las personas. Esta situación, además, deteriora la vigencia y efectividad del sistema legal en general, dificultando las transacciones, encareciendo el acceso al bien justicia (lo que lo convierte en un "bien" más escaso) y contribuyendo innecesariamente a aumentar el malestar en la sociedad ${ }^{3}$. La tardanza en la puesta en marcha de dichas reformas, o la

\footnotetext{
${ }^{1}$ Una Encuesta Cep (2002) mostró que en el caso de los Ministros de la Corte Suprema, un 15\% de la población declaraba tenerles confianza en 1992, mientras que en el 2002 este porcentaje bajó al 7\%. Asimismo, la misma encuesta arrojó que un 33\% de la población consideró que en el Poder Judicial hay mucha corrupción. Además, entre las instituciones que reciben menos confianza se encontraron los Tribunales de Justicia. Un panorama similar se observa en la Encuesta Cerc (2005), según la cual el Poder Judicial está entre las instituciones en las cuales las personas más han perdido su confianza entre el año 1990 y el 2005. Por otra parte, según la encuesta Latinobarómetro (2003), encuesta que se realiza a 18 países de Latinoamérica desde 1996, el Poder Judicial chileno ocupa el décimo lugar en comparación con los demás países en relación a la confianza que le tienen los ciudadanos. A esto se suma el hecho que las personas que declaran tener "mucha" y "algo" de confianza en el Poder Judicial chileno disminuyen de 35,6\% en 1996 a 23,1\% en el 2002. En tanto, en la Encuesta de Corrupción de Libertad y Desarrollo (2005) el Poder Judicial ocupó el primer lugar en cuanto a Percepción del Nivel Corrupción en las distintas Instituciones.

2 Según el Estudio de Acceso a la Información Pública realizado por la Corporación Participa (2004), la Corte Suprema de 8 peticiones de Información no entregó respuesta en 7 casos, y en un caso no se pudo entregar la consulta. En cuanto al Poder Judicial de 13 consultas 12 no se respondieron y un caso no se pudo entregar. Por lo tanto, el Poder Judicial no respondió ninguna de las consultas, siendo la institución pública peor evaluada en cuanto al acceso a información. En tanto, según el estudio Barómetro de Acceso a la Información, de la Universidad Diego Portales (2004), encuesta a periodistas y editores, el Poder Judicial es el frente informativo en el que existen mayores dificultades para acceder a información en Chile. La importancia de esta situación, agrava y perpetúa la aguda crisis de credibilidad, legitimidad y confianza que atraviesa este poder del Estado, lo que por ahora hace redundante e innecesario cualquier comentario o juicio de valor adicional.

3 Siguiendo a Santos Pastor, los procesos de reforma judicial, y en este caso, a la justicia civil, son en extremo aconsejables "cuando la situación presente ocasiona graves desprotecciones de derechos, generando inhibiciones de actuaciones socialmente provechosas (por ejemplo, inversión y producción) u ocasionando derroche y conflictividad, y porque existen alternativas factibles para evitarlo, aunque, como en otras políticas públicas, su respaldo social no sea unánime. Sin una justicia independiente, eficiente y competente no hay derechos, ni se celebran contratos -o hay menos de los que podría haber-y por lo tanto no se genera el bienestar que aquellos comportan. En pocas palabras, sin una razonable efectividad de la justicia la sociedad padece injustificadamente". (PASTOR, 1997, p. 87).
} 
implementación de reestructuraciones mal financiadas, incompletas o erróneamente diseñadas, puede llevar a debilitar aún más la percepción que las personas tienen en la Justicia, con todas las negativas consecuencias que ello genera en la convivencia y en el funcionamiento institucional de nuestra sociedad. Además, los procesos de reforma judicial pueden ser un antídoto efectivo contra la corrupción del sistema judicial ${ }^{4}$.

Afortunadamente, nuestro país hoy cuenta con un gran activo en materia de reformas judiciales: la Reforma Procesal Penal marcó un giro radical en el tipo de discusión y análisis relativo a las políticas públicas de administración de justicia, logrando que sean incorporados argumentos, principios y conceptos económicos y de política pública que están complementando y enriqueciendo los paradigmas que dominaron por largos años la cultura jurídica nacional. Ello da cuenta de un profundo proceso de cambio cultural, que debe seguir siendo ampliado y profundizado en los años sucesivos.

\footnotetext{
${ }^{4}$ Para Buscaglia "en el sistema de justicia la corrupción adquiere la forma de soborno, presiones políticas e influencias personales a diferentes niveles. Está estrechamente vinculada con problemas de infraestructura: salarios bajos, inestabilidad en el ejercicio del cargo, ausencia de una evaluación profesional basada en los méritos, y también las practicas largamente establecidas de que la ley no se aplica a todos por igual (...) Si combinamos esto con una tradición de impunidad en los cargos públicos, encontramos entonces un obstáculo formidable para la reforma legal efectiva". (BUSCAGLIA, 1997, p. 42).

Nos parece evidente que uno de los mecanismos más eficientes de control de la corrupción descansa en una judicatura independiente, procedimientos imparciales, capaces de hacer cumplir las leyes y los contratos, de interpretar la ley en forma uniforme y razonada y de garantizar por igual los derechos de los ciudadanos. La judicatura es la que tiene la última palabra en la determinación de lo prohibido y permitido, y de lo sancionable. La relación del sistema judicial con la corrupción es por tanto doble: se presenta como causa y como solución. Por otro lado, la debilidad e ineficiencia del Poder Judicial tiene una directa incidencia en la vigencia del Estado de Derecho y en el respeto de la ley. Además, ello está vinculado con la confianza que los ciudadanos tengan en sus autoridades e instituciones, así como en la conveniencia de cumplir con las normas y denunciar a quienes las infringen. Algunos autores han señalado que la dimensión más grave de Latinoamérica es "la ausencia de respeto a las leyes y la falta de medidas de control de la corrupción”, y que los países más ricos -Argentina, Brasil, México y Venezuela- se encuentran entre aquellos con problemas más profundos de respeto a las leyes.

La independencia del Poder Judicial frente al Ejecutivo es una garantía de control de corrupción. La influencia que pueda tener el Ejecutivo en nombramientos, calificaciones, ascensos, selección, determinación de honorarios y beneficios, así como en la aplicación de sanciones y en la forma de aplicar la ley (incluyendo procedimientos y eficiencia), son factores que pueden contribuir a un aumento o disminución de la corrupción. Más aún, la confianza en la vigencia de la ley, debidamente resguardada por un Poder Judicial vigoroso e independiente, aumenta el "costo" asociado a una práctica corrupta. Por el contrario, la posibilidad de actuar abusivamente, aumenta si existe la sensación de que es posible controlar o influir a los tribunales en sus decisiones finales.

El Poder Judicial en América Latina es percibido como una de las instituciones menos creíbles y menos confiables, y muchas veces son las mismas autoridades que se benefician de esta relación, las que muestran poco entusiasmo a la hora de impulsar modificaciones que fortalezcan la autonomía de los tribunales y la protección de los ciudadanos frente a los abusos de poder. Evitar la corrupción o disminuir la sensación de impunidad frente a actos ilegítimos y abusivos, supone permitir la existencia de un sistema auténtico de administración de justicia imparcial, que tenga por objeto aplicar la ley y solucionar las diferencias entre los ciudadanos en una sociedad. Nos parece que para un gobernante es de suyo una actitud corrupta el permitir la existencia de una justicia "manipulable" o "presionable", dúctil a los intereses de un determinado grupo político. En cierta medida ello implica considerar a la justicia como una extensión del poder y no como un límite.
} 
En efecto, la tendencia mayoritaria a la hora de analizar el sistema de administración de justicia ha adoptado lógicas un tanto ingenuas, concibiéndola como aquella herramienta que mecánicamente asegura el imperio y vigencia de la ley, así como la concreción de un fin superior y trascendente: la justicia. De este supuesto, se sigue que la justicia debe ser concedida y "garantizada" a todos por igual y sin graduaciones, imponiendo así a esta función pública una misión y una expectativa que desgraciadamente, le resultará imposible de alcanzar en cualquier punto del planeta y en cualquier momento de la historia. Durante años, muchos análisis en el área de justicia minimizaron la evidencia y soslayaron un principio básico de la acción política, que nos dice que no siempre es posible hacerlo todo, de que lo mejor es enemigo de lo bueno y que es necesario asumir que los recursos son escasos y tienen usos alternativos, por lo que se hace necesario decidir cuánto de este bien justicia deberá ser "postergado" en función de otros bienes socialmente prioritarios. Por ser este un trabajo que pone su acento en el análisis económico del derecho, más adelante nos referiremos a este punto con mayor detención.

\section{ASPECTOS NORMATIVOS Y POSITIVOS DE LA JUSTICIA CIVIL EN CHILE}

\section{1. ¿QUÉ DEBEN CONOCER LOS TRIBUNALES CIVILES?}

Aunque parezca una cuestión básica, es sumamente relevante responder, desde un punto de vista normativo, cuál es el rol de los tribunales de justicia. Esta cuestión resulta fundamental al momento de analizar si los tribunales civiles se están abocando a materias propias de su función jurisdiccional, o por el contrario, si parte de su funcionamiento deficitario se debe a que absorben funciones que bien podrían ser asumidos por otros organismos. En este sentido, parece evidente que la labor de un juez no debe ser otra que la de declarar el derecho frente a un conflicto entre partes ${ }^{5}$. Ello tiene como objetivo principal contribuir a generar y mantener la confianza ciudadana en la vigencia del Estado de Derecho, lo que permite generar un estándar básico de seguridad y certeza jurídica, evitando la autotutela y reduciendo los costos de transacción entre las personas ${ }^{6}$.

\footnotetext{
5 A modo de ejemplo, un autor nacional: "La misión propia del juez es, ya la determinación del castigo merecido por quien ha infringido el ordenamiento jurídico -jurisdicción en lo criminal-, ya la decisión de alguna disputa sobre relaciones e intereses privados en orden al estado de las personas, a la herencia, régimen de familia, condición de los bienes y de los contratos, jurisdicción en lo civil (...). Han de entenderse también comprendidas en la jurisdicción que se entrega a un tribunal, las facultades de disponer y realizar todo cuanto lleve a la entera y cumplida ejecución de lo que haya sido resuelto, ya sirviéndose de los propios medios de que disponga, ya requiriendo el auxilio de otros órganos que tengan la obligación de proporcionarlos. De esta manera se consagra lo que constituye el imperio de la justicia, sin el cual sus decisiones se hacen del todo ineficaces". (SILVA BASCUÑán, 1997, pp. 524-525).

${ }^{6}$ En este sentido, los costos de transacción son "los costos derivados de negociar y hacer efectivos los acuerdos de cooperación”. (LARROULET y MOCHON, 2003, p. 259). Sería más preciso decir que la realización de transacciones e intercambios supone un orden social dado, y la ausencia de confianza en este, conllevaría a la ausencia de transacciones.
} 
Igualmente, las realidades más complejas que enfrenta actualmente la sociedad, requieren de una institucionalidad jurídica que sea compatible con las exigencias de funcionamiento de los mercados internacionales, que garantice el cumplimiento de los contratos y el respeto a los derechos de propiedad de los individuos, a través de mecanismos conocidos, expeditos e imparciales, y que promueva la cooperación entre los agentes privados. Un esquema institucional que mantenga la incertidumbre por largos períodos de tiempo, y cuyas sentencias no sean capaces de mostrar el verdadero alcance de las normas y generar certeza de su contenido mediante un sistema jurisprudencial uniforme, no tan solo puede contribuir a crear ineficiencias económicas, sino a limitar el crecimiento económico ${ }^{7}$.

Asimismo, es necesario considerar que los tribunales de justicia son la última ratio del eslabón de los sistemas de solución de controversias que tiene una sociedad, y las buenas o malas decisiones judiciales generarán un impacto ex ante sobre las expectativas de los individuos ${ }^{8}$, incentivando o desincentivando conductas, como por ejemplo, la redacción de contratos más completos y con menores espacios para la interpretación; el establecimiento de cláusulas de arbitraje; la disminución de los incumplimientos "estratégicos" frente a una aplicación homogénea y rigurosa de la ley y un sistema que sanciona rápida y decididamente el incumplimiento de los acuerdos, etc. ${ }^{9}$.

\section{2. ¿QUÉ ESTÁN CONOCIENDO LOS TRIBUNALES CIVILES?}

\subsubsection{Aumentan los ingresos de causas}

Si bien la congestión y lentitud de los tribunales es una realidad indiscutida, desde un punto de vista empírico existe escasa información que permita cuantificar en forma

\footnotetext{
${ }^{7}$ Existe amplia literatura y evidencia empírica comparada en este sentido. Por ejemplo, para la denominada Nueva Economía Institucional, iniciada por Douglas North, el mercado no funciona en el vacío, puesto que para que las transacciones se produzcan, y con ello una eficiente asignación de los recursos, se requiere de un conjunto de instituciones que lo hagan posible. Tales instituciones pueden tener tanto un carácter formal, como lo son las leyes y los organismos, como uno informal, como lo es todo el espectro cultural de una sociedad. Al respecto ver NORTH (1981) y (1990). Asimismo ver NORTON (1998).

Existe una creciente literatura en el ámbito "Derecho y Desarrollo Económico" (Law and Economic Development), que siguiendo los trabajos de Douglas North, vincula las escuelas económicas de desarrollo económico y Economía Comparada con el análisis económico del derecho, correlacionando empíricamente, y con bastante éxito, el impacto de los sistemas legales, judiciales e instituciones jurídicas en el crecimiento y desarrollo económico, argumentando que las instituciones legales son decisivas para alcanzar estos. Más recientemente, se ha desarrollado una línea de investigación en Derecho y Mercados Financieros (Law and Finance). En este sentido ver, SHERWOOD et al. (1994); LEVINE, (2003); LA PORTA et al. (2003) y (1998); MAHONEY (2001); y DAM (2006a), (2006b) y (2006c).

En este sentido, Sherwood analiza cuánto constriñe el desempeño económico de un país un sistema judicial que funcione deficientemente: “¿Podría ser tanto como el 15? En otras palabras, si un país tuviera que crecer presumiblemente a un ritmo de, digamos, el 3\%, ¿crecería solo el 2,6\% si su sistema judicial funcionara deficientemente? Algunos economistas, quienes han observado detenidamente las economías nacionales de numerosos países de América Latina y han empezado a examinar algunos aspectos del desempeño del sistema judicial, sugieren que el efecto podría llegar a 15\%”. (SHERWOOD, 1997, p. 54 (n.3).

8 Posner (2000) y (1981); CoOter y Ullen (1988); BAird et al. (1994); POlinsky (2003) y Shavell (2004).

${ }^{9}$ (Posner, 2000, pp. 29-30).
} 
precisa su magnitud, lo que debe ser considerada como una carencia insostenible para una sociedad que ha manifestado transversalmente su voluntad de iniciar un proceso de reforma a la justicia civil. Con todo, en base a la escasa evidencia empírica disponible, se puede observar que entre 1973 y 2005 el aumento porcentual de los ingresos civiles llegó a $1281 \%^{10}$ (Gráfico No 1). Solo entre 2000 y 2005 el aumento de los ingresos civiles fue de 58\%, es decir, de casi 630.000 ingresos se llegó a prácticamente $985.000^{11}$.

\section{GRÁFICO No 1}

Evolución causas civiles ingresadas nacional 1973-2005

(Fuente: Elaboración propia en base a Mery 2003 y Corporación Adm. Poder Judicial)

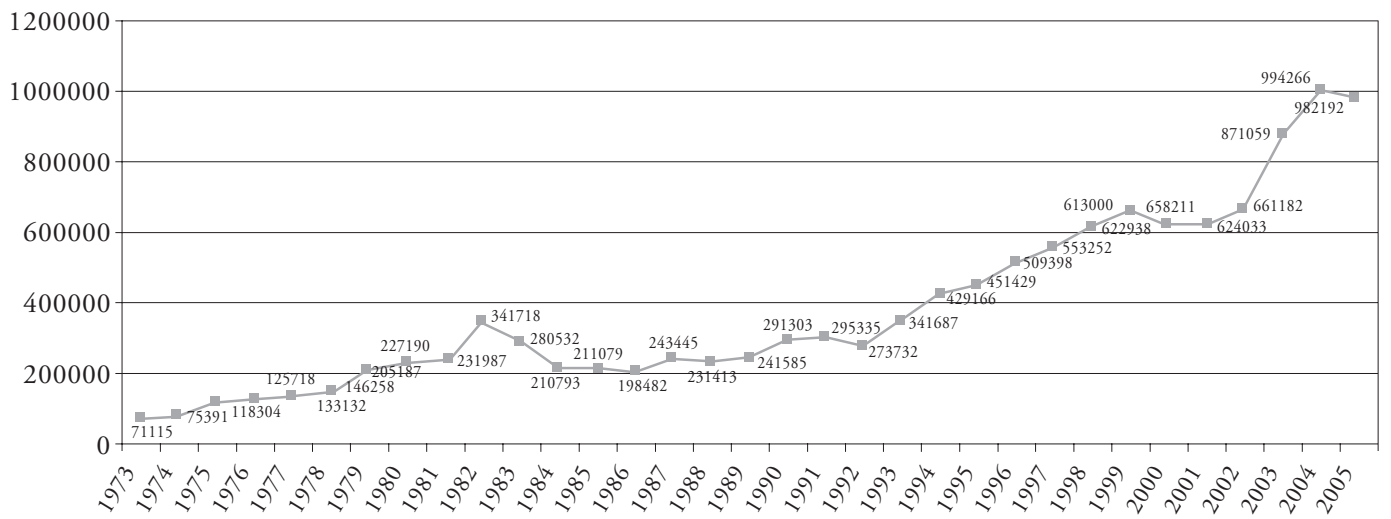

Respecto a las causas de este progresivo y sostenido aumento en el número de ingresos civiles, a priori es poco probable equivocarse al sostener que el actual diseño institucional puede tener una responsabilidad importante. En este sentido, la falta de racionalidad (costos e incentivos) para utilizar o no el sistema judicial; la creación y dispersión de recursos y acciones; la falta de tasas y costas efectivas; la impredecibilidad de las sentencias y por lo mismo del resultado del pleito (aún existiendo casos previos similares) y la nula responsabilidad de abogados y jueces, parecen ser todas buenas razones para sobreutilizar los tribunales civiles. Así las cosas, es fácil intuir que se generan incentivos para abusar del litigio como estrategia de negociación, en la medida en que su actual estructura permite dilatar el cumplimiento de las obligaciones o bien, negociar una mejora en las condiciones de cumplimiento, aprovechando como un activo propio todo el tiempo y el esfuerzo (económico y moral) que exige a la contraparte recurrir a los tribunales para exigir el cumplimiento forzoso de una obligación, ofreciéndonos un ejemplo de un sistema procesal que favorece el abuso, vuelve más precarios los

\footnotetext{
10 MERY (2003)

11 Elaboración propia en base a las estadísticas entregadas por la Corporación Administrativa del Poder Judicial.
} 
derechos y debilita el imperio de la ley. Mery elabora algunas hipótesis que también podrían explicar el fuerte aumento de los ingresos de causas civiles en los últimos años. Entre estas considera el desarrollo y crecimiento económico, la conciencia y democratización ciudadana, la explosión demográfica, el proceso de modernización del Estado y el aumento en el número de abogados ${ }^{12}$.

Asimismo, debe considerarse que los aumentos de los ingresos civiles presenten variaciones importantes en el período analizado (Gráfico 2).

\section{GRÁFICO No 2}

Variación de ingresos civiles judiciales nacional 1973-2005

(Fuente: Elaboración propia en base a Mery 2003 y Corp. Adm. Poder Judicial)

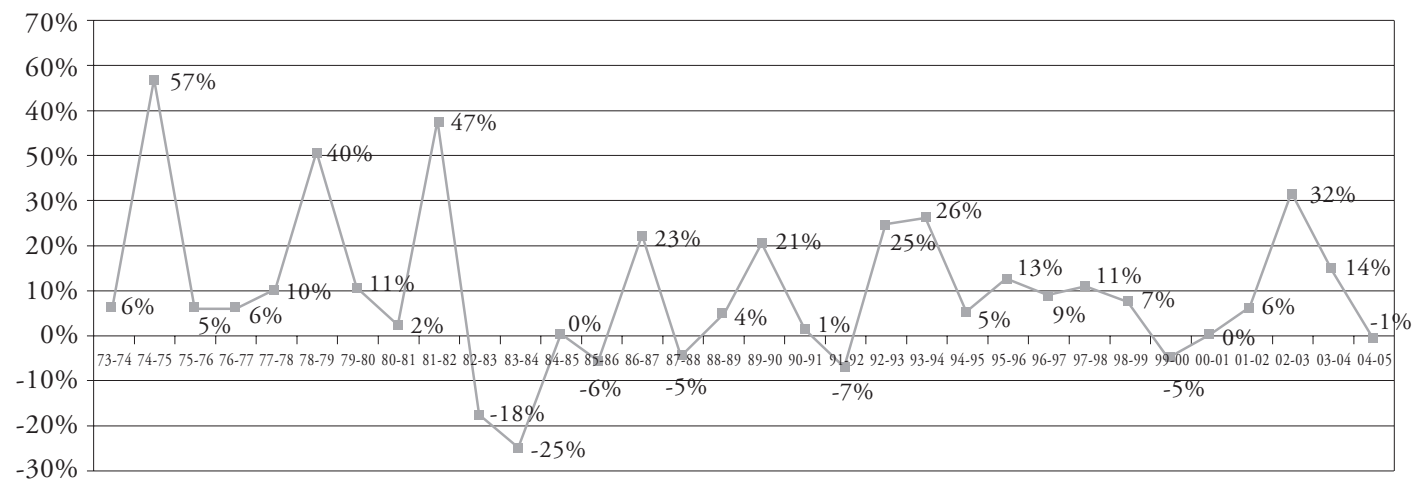

Por otro lado, la falta de estadísticas e investigaciones empíricas también alcanzan un área clave en esta materia: los tiempos de duración de los juicios, lo que hace difícil analizar en detalle el impacto de los ingresos de causas civiles en el tiempo ${ }^{13}$.

\footnotetext{
12 Al respecto ver MerY (2003) pp. 13-26.

13 Uno de los escasos estudios que se dispone fue realizado por el Ministro Carlos Cerda a comienzos de los años 90. Dicho trabajo intentó medir la duración de los juicios civiles ordinarios en los juzgados de Santiago y comparar su evolución en el tiempo a partir de una investigación similar efectuada en 1976. Este estudio se basó en información de 1989, a partir de una muestra aleatoria de 685 expedientes de ocho juzgados civiles de la capital y concluyó que la duración media de ambas instancias, en un procedimiento civil ordinario, es de 1.009 días. De este total más de 700 días están constituidos por aquellos en los cuales el proceso se paraliza a la espera de que el juez dicte resoluciones de fondo. Posteriormente, se comparó esta duración media con aquella determinada en 1976, que fue de 806 días. En dicho estudio también se señala que en 1976 había solo 7 juzgados civiles de mayor cuantía en Santiago, en lugar de los 30 que funcionaban en 1991. En otros términos, esto significa que entre 1976 y 1991, se cuadruplicó el número de tribunales, sin que ello contribuyera a la reducción del tiempo medio de los procesos. La investigación trató de medir, también, la incidencia de la Ley 18.705 de 1988, que modificó el Código de Procedimiento Civil, con el objeto de agilizar el procedimiento civil ordinario. Se analizaron más de 55 expedientes de causas que se iniciaron después de la dictación de la Ley (julio de 1988) y se comprobó que estas tuvieron una duración media de 500 días. En este caso, la dictación del cuerpo legal contribuyó a agilizar parcialmente el procedimiento judicial, pero resultó ser del todo insuficiente para solucionar los problemas de congestión que enfrentan los tribunales. CERDA (1992).
} 
¿Qué se puede esperar para el futuro en materia de ingresos civiles? Si se proyecta en base al aumento 2000-2005, y considerando la variación 2004-2005; se puede esperar que para el 2010, los ingresos al sistema superen los 1.435.000, demanda que de no mediar reformas estructurales radicales importarían niveles de atochamiento críticos.

\subsubsection{Trabajo jurisdiccional: Tipos de Causas}

Más preocupante aún resulta la evidencia respecto a qué tipos de causas (materias) están conociendo los tribunales ${ }^{14}$. Una de las escasas investigaciones empíricas existentes mostró que el promedio de la distribución de causas civiles ingresadas totales entre 1977 y 1995 , se repartía en $61 \%$, cobranzas; $13 \%$, otras contenciosas; $6 \%$, manifestaciones y pedimentos mineros; $8 \%$, herencias; $8 \%$, otras voluntarias; y $4 \%$, familia ${ }^{15}$. Si se realiza este mismo análisis para 2003, dicha distribución corresponde a 67\%, cobranzas; $9 \%$, otras contenciosas; 7\%, manifestaciones y pedimentos mineros; $4 \%$, herencias; $2 \%$, otras voluntarias; y 11\%, familia. Un resultado bastante similar se observa si se analiza el promedio $1995-2003^{16}$. De las cifras anteriores se puede concluir, en primer lugar, que la distribución de los ingresos en el período 1977-2003 no ha variado sustancialmente, excepto en el caso de las causas de familia, en que el aumento sí es importante ${ }^{17}$.

Más recientemente, el Presidente de la Corte Suprema sostuvo que "aun cuando es indesmentible el estado de saturación que reina en los juzgados civiles de nuestro país y que de ello solo se suele responsabilizar al Poder Judicial, sirve de antecedente que durante el año 2003, en los juzgados civiles de Santiago -esto es en primera instancia - los procedimientos allí radicados tuvieron una duración aproximada de 300 días, o sea, casi un año. Obviamente, algunos procedimientos son de tramitación más rápida, como los ejecutivos o los no contenciosos y otros en cambio, son esencialmente más complejos y técnicos, lo que importa aumentar los tiempos de tramitación". Discurso pronunciado en el Seminario "Justicia Civil: Una Reforma Pendiente" (2004), organizado por la Facultad de Derecho de la Pontificia Universidad Católica y Libertad y Desarrollo. Con todo, una investigación reciente de alumnos de la Facultad de Derecho de la Universidad Católica arroja resultados bastante diferentes a estos últimos. La investigación de los alumnos Carolina Hernández, Gonzalo Manzano y Javier Sajuria, consistió en el análisis de 186 causas tomadas aleatoriamente de 13 juzgados civiles de Santiago que se encontraban archivadas por diversos motivos entre los años 1998 y 2002. El promedio de la duración de los procedimientos fue el siguiente: 785,2 días- Ejecutivo; 2009,4 días -Ordinario; 707,4 días-Sumario; y, en promedio 1.066 días. Todas estas cifras incluyen la duración desde que la causa ingresó al Tribunal hasta que termina por sentencia definitiva o algún equivalente jurisdiccional, o se archiva por abandono de procedimiento.

${ }^{14}$ Los procesos civiles pueden ser agrupados, a grosso modo, en asuntos voluntarios y asuntos contenciosos Los asuntos no contenciosos o voluntarios son las gestiones que se realizan ante un tribunal con el objeto que el juez reconozca una situación determinada y en la que no existe un legítimo contradictor (por ejemplo, la rectificación de una partida de nacimiento o la constitución de propiedad minera). En los asuntos contenciosos, en cambio, existe un derecho que se discute entre dos o más partes y donde se solicita la intervención del juez para dirimirla (por ejemplo, en el cumplimiento de una obligación).

15 VARGAS et al. (2001).

16 Elaboración propia en base a estadísticas proporcionadas por la Corporación Administrativa del Poder Judicial.

${ }^{17}$ Este incremento se debe principalmente al aumento de las causas de violencia intrafamiliar. En efecto, el aumento de las causas de familia pasa desde el $4 \%$ en el promedio $1977-1995$ a cerca del $11 \%$ en el período 1995-2003. Sin embargo, con la reforma a la justicia de familia, estas causas salen del sistema civil el año 2005. 
En el caso específico de las cobranzas, si bien en 2003 representan el 67\% de los ingresos, el promedio $1995-2003$ es 61\%, porcentaje similar al promedio 1977-1995. Además, del total de los ingresos contenciosos del período 1995-2003, las cobranzas representaron en promedio el $85 \%$ (Gráfico 3$)^{18}$.

\section{GRÁFICO No 3}

Incidencia de las cobranzas sobre ingresos judiciales totales: 1995-2002

(Corporación Administrativa del Poder Judicial)

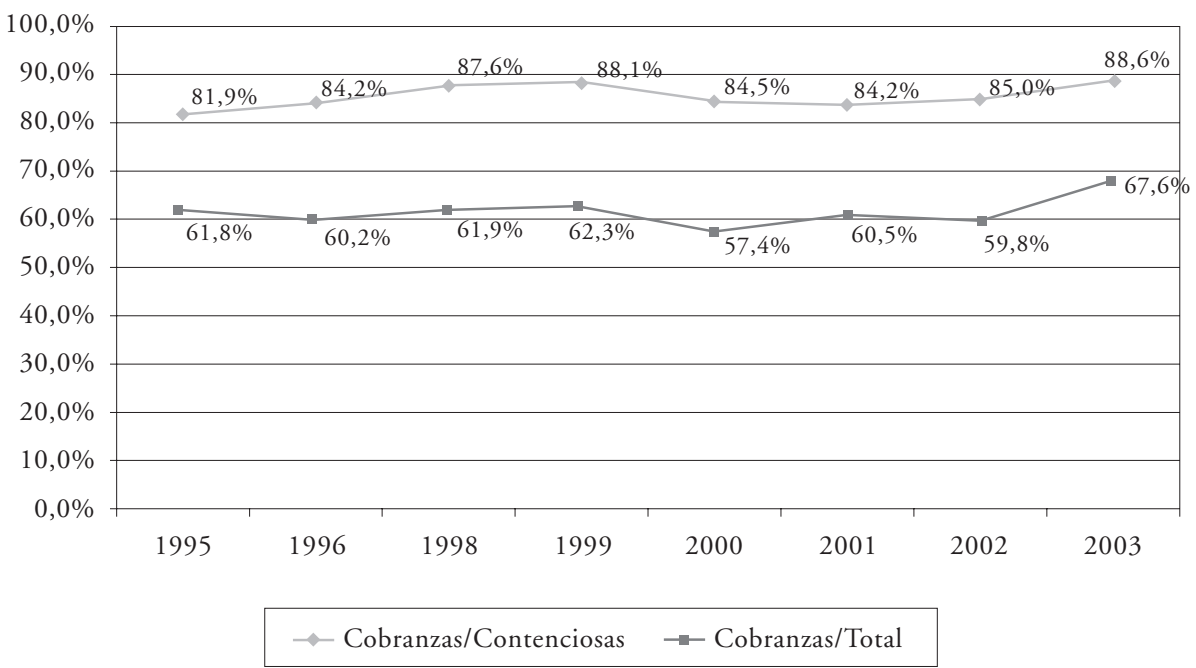

Las estadísticas además confirman la percepción de que los tribunales civiles se están abocando mayoritariamente al conocimiento de materias que no requieren de una decisión jurisdiccional. Este es el caso de las cobranzas judiciales, y en general, de todos aquellos donde solo reste la ejecución de una obligación no discutida. Evidentemente, estos pueden derivar en una controversia jurídica, si la parte ejecutada cuestiona de alguna manera legalmente aceptada, el mérito ejecutivo del título invocado. En este sentido, si a la lentitud de los procesos sumamos los costos de litigación (honorarios de los abogados, notificaciones, producción de pruebas y demás costos del proceso) es posible que la cobranza judicial de obligaciones de bajo monto sea muy poco factible, lo cual explica en parte el alto número de causas que son abandonadas y archivadas antes de su completa tramitación. Más aún, de mantenerse esta situación en el tiempo, podría generarse la percepción de que la probabilidad de ser obligado a cumplir lo pactado en muchos casos es baja, estimulando el no cumplimiento de las obligaciones contraídas, y como consecuencia de ello, la reticencia a contratar y mantener relaciones comerciales

18 Elaboración propia en base a estadísticas proporcionadas por la Corporación Administrativa del Poder Judicial. 
con personas de menores ingresos. Asimismo, no se tiene información sobre el volumen de las oposiciones en los juicios de cobranzas, pero sí se utiliza como patrón la evidencia del derecho comparado, estas no debieran superar el $15 \%{ }^{19}$.

Respecto de los asuntos voluntarios (o no contenciosos), se observa que caen en su participación relativa de los ingresos civiles desde un $20 \%$ en el promedio $1977-1995^{20}$ al 15\% en el promedio 1995-2003, los cuales constituyen un porcentaje relevante de los ingresos civiles totales ${ }^{21}$. Además, si bien la tendencia en el período 1995-2003 es a una baja en la participación relativa de los asuntos voluntarios respecto del total de causas, en el año 2003 sigue siendo dicha participación del $13 \%{ }^{22}$, lo que implica la utilización del "sistema judicial" en un importante número de casos en que más bien se están requiriendo los servicios de un órgano administrativo.

\subsubsection{Motivos de Término}

Si se analiza la evidencia, se observa que el promedio 1999-2002 respecto de los 30 juzgados civiles de Santiago muestra que menos de un 9\% de los términos se encuentran en una sentencia definitiva (Gráfico 4$)^{23}$. Con todo, quedan muchas interrogantes respecto de los otros tipos de términos. En este sentido, llama la atención el 66\% de causas archivadas. Dado que la evidencia no especifica los motivos de archivo, se hace difícil entregar una explicación de dicho alto porcentaje. Con todo, se podría hipotetizar -en el mismo sentido en que se hizo respecto de las causales en el aumento de ingresos de causas civiles en los últimos años- que el diseño institucional incentiva el uso de los tribunales civiles como parte de una estrategia de negociación, que las partes se ven forzadas a superar sus diferencias en tiempos menores que los que toma el litigio, o que sean muchos los casos donde la utilización del sistema judicial sea para el actor más costoso que el abandono de su pretensión ${ }^{24}$.

\footnotetext{
19 Respecto de estadísticas del derecho europeo en la materia, sobre la base de los procedimientos monitorios, se establece que en Francia el rango de oposición es de un 5\%; en Italia, el 10\%; en Alemania, con 7,4 millones de mandatos de pago, tienen un nivel de oposición del 11\%; y en Austria, el 10,15\%. Estadísticas presentadas por José Pedro Silva en su presentación en el Seminario "Justicia Civil: Una Reforma Pendiente"

20 VARGAS et al. (2001)

${ }^{21}$ Elaboración propia en base a estadísticas proporcionadas por la Corporación Administrativa del Poder Judicial.

${ }^{22}$ Elaboración propia en base a estadísticas proporcionadas por la Corporación Administrativa del Poder Judicial.

23 Elaboración propia en base a estadísticas proporcionadas por la Corporación Administrativa del Poder Judicial.

${ }^{24}$ Existe también en Chile un problema asociado, que podría tener un alto impacto en la cantidad de ingresos judiciales y en la recarga del sistema, vinculado con el tratamiento tributario de los créditos incobrables (donde el acreedor es obligado a demandar -aún sin una real expectativa de obtener un resultado- para no ser sancionado tributariamente). Existe actualmente un proyecto de tesis de grado, del alumno Guillermo Frene, guiado por los profesores Juan Cristóbal Jaramillo y Francisco Javier Leturia, que desarrollará esta materia).
} 


\section{GRÁFICO No 4}

Causales de Término en 30 Juzgados Civiles de Santiago: Promedio 1999-2002

(Corporación Administrativa del Poder Judicial)

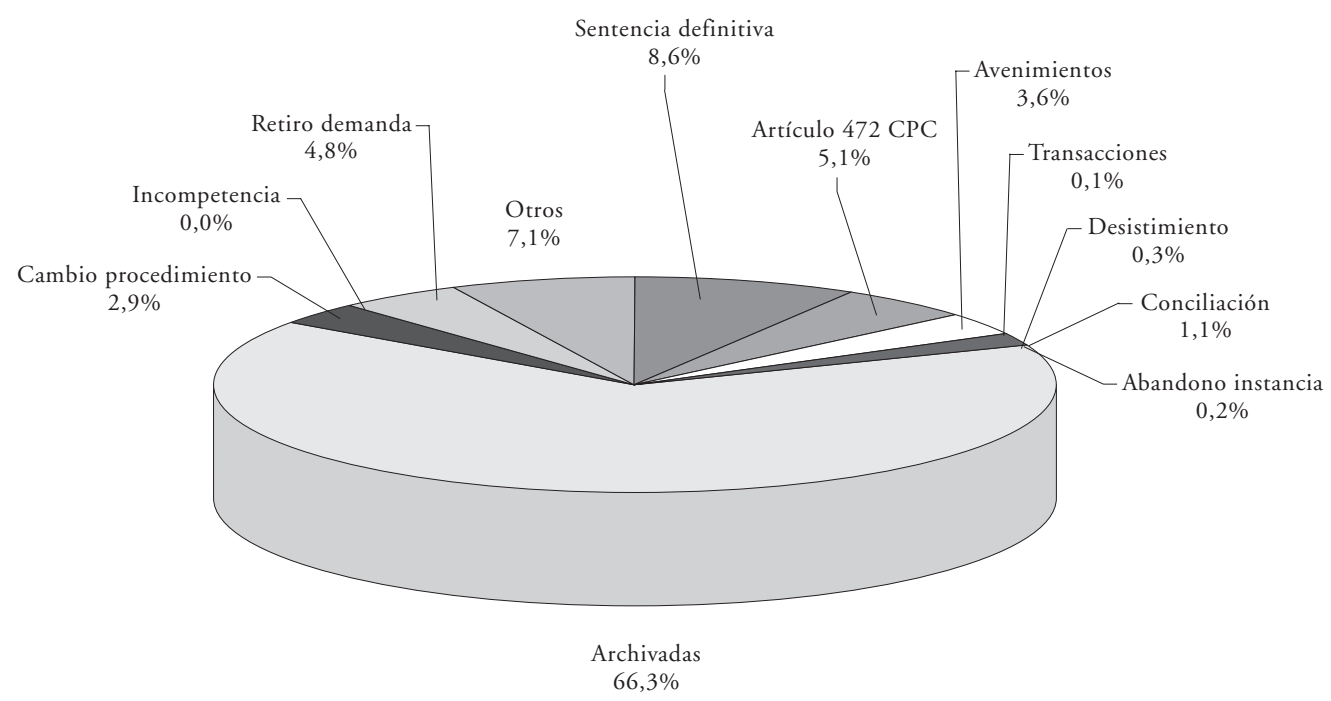

Asimismo, los datos analizados muestran el bajo éxito de la conciliación, lo cual permite al menos dos reflexiones. En primer lugar, en el actual esquema de congestión de los tribunales civiles se hace virtualmente imposible el que los jueces tengan el tiempo suficiente como para estudiar el caso antes del probatorio y proponer a las partes las bases de un acuerdo. Esta dificultad se agudiza aún más por la ausencia de una cultura adecuada a este propósito. Así las cosas, en la práctica, la conciliación ha pasado a ser un trámite más del juicio, sin mayor utilidad, donde los esfuerzos de las partes por lograr un acuerdo constituyen la excepción. Una segunda reflexión dice relación con cómo la instauración de la conciliación como un trámite obligatorio constituye un buen ejemplo de una política pública que ha resultado ser poco aplicable y solo residualmente conveniente en la realidad. Ello es una muestra de que en estas materias la racionalidad, el pragmatismo y la prudencia deben ser el norte y el oriente de los procesos de reforma, siendo los buenos deseos y las propuestas ligeras un aporte demasiado insuficiente para la problemática que se busca regular. 


\section{LA JUSTICIA CIVIL A LA LUZ DEL ANÁLISIS ECONÓMICO DEL DERECHO}

Cualquier proceso de reforma a la justicia civil, como cualquier discusión en el mundo de las políticas públicas debe ser analizado desde una óptica interdisciplinaria. De lo contrario, se corren graves riesgos en no acertar adecuadamente con el diagnóstico correcto, lo que tiene consecuencias negativas desde el punto de vista del diseño e implementación de estas reformas, o lo que es lo mismo, deterioran la vida social e individual. En este sentido, parece clave avanzar y profundizar en análisis de la justicia civil chilena desde un punto de vista económico, en particular, en lo que dice relación con los incentivos y efectos que enfrentan las partes en un litigio civil 25.

Bajo este marco teórico, una primera pregunta será ¿cuánto de bien público posee la justicia civil y cuánto de bien privado? ${ }^{26}$ Las implicancias derivadas de este análisis serán decisivas, ya que si llegamos a la conclusión de que la justicia civil presenta un alto componente de bien privado, deben ser las partes las que asuman los costos de litigar mediante el establecimiento de un sistema, por ejemplo, de tasas de litigación ${ }^{27}$, liberando al Estado de asumir esa carga (lo que significaría, además, la más revolucionaria de las propuestas que en este trabajo se han insinuado). Sin embargo, además de los aspectos culturales, ello también supone desafíos en materia de acceso a la justicia, que deben ser debidamente abordados. Por otro lado, si la justicia civil planteara elementos de bien público, ello importaría incorporar al Estado en cuanto a su financiamiento y diseñar la fórmula de la participación en este, por ejemplo, a través de subsidios.

En este sentido, creemos que la justicia civil se comporta, desde un punto de vista económico, tanto como un bien privado con externalidades positivas, como un bien público. Por un lado, el ser privado implicaría que la justicia civil tiene por objeto fundamental resolver un asunto cuya titularidad, causalidad y efectos son de interés privado o particular; por lo tanto, el financiamiento total del sistema correspondería a los demandantes (mediante el cobro de tasas fijas o por actuaciones).

\footnotetext{
25 Este análisis ha sido largamente desarrollado desde la óptica del análisis económico del derecho. Al respecto ver SHAVELL (2004a) en especial el capítulo 17, (1982) y (2003); POSNER (2000) en especial el capítulo 21 y (1973); COOTER y Rubinfield (1989); Bundy y ElHAuge (1991); KAPLOW y SHAVELL (1989); Landes (1971); POlinsky y SHAVEll (1989); y Hua y SPIER (2004).

${ }^{26}$ Esta cuestión también es analizada en VARGAS et al. (2001).

27 El tema de las tasas judiciales es tratado en extenso y desde una perspectiva comparada por Vargas (2005). Por otra parte, Buscaglia considera las tasas judiciales como un mecanismo que por su naturaleza puede disminuir los incentivos de la corrupción en el sistema judicial: "En muchos países dentro de la región, la Constitución proporciona un sistema legal gratuito sin cargas oficiales de ningún tipo. A pesar de que los tribunales son teóricamente accesibles para todos, la abolición de las tasas contribuye en parte al problema de bajos salarios, ineficacia y baja calidad de la justicia. La falta de tasas legales formales crea incentivos para que los empleados de los tribunales carguen tasas no autorizadas a las partes. Un litigante puede considerar, o recibir la solicitud de pagar una tasa con el fin de adelantar el caso. Esta transacción monetaria no beneficia al sistema judicial ni mejora los costos legítimos del mantenimiento de un sistema judicial, sino que muy sencillamente va en beneficio personal de un juez o funcionario judicial. Esto contribuye a la corrupción del sistema y en la práctica niega el acceso a tribunales". BUSCAGLIA (1997) p. 38 (n.14).
} 
Asimismo, la justicia produce una externalidad positiva: el efecto disuasivo que genera la confianza en la vigencia del Estado de Derecho y que beneficia a un gran número de individuos, los cuales no incurren en los costos directos que provoca ingresar al sistema judicial -tasas judiciales, tiempos de espera-, lo cual justificaría un subsidio estatal. Por otro lado, el ser bien público ${ }^{28}$ está dado por la generación de jurisprudencia (predecedentes), lo que es información para la sociedad (los agentes económicos) del contenido del sistema normativo, de su eficacia, de sus límites, del sentido con que se interpretará una determinada norma jurídica, sobre cómo se resolverá una determinada controversia que tiene ciertas características, sobre la forma de evaluar las pruebas, etc.

En nuestro país, tradicionalmente se ha enfrentado la reforma al sistema judicial desde un punto de vista de la oferta, esto es, se ha sostenido que frente a los problemas que comúnmente aquejan a la justicia, como son la congestión y la dilación, la respuesta adecuada pasa por un aumento en el número de tribunales y en la dotación de personal. Poner el eje de las esperanzas de modernización, perfeccionamiento y aumento de eficiencia en esta solución, constituye un error y quizás la razón de muchos de los problemas que enfrenta el sistema de justicia chileno. Una política pública correcta en materia de justicia, además de preocuparse de la oferta del servicio judicial, debe enfrentar el problema de la demanda por justicia, identificando los principales incentivos que entrega el sistema para que los particulares recurran a ella y, solo a partir de esto, poder

${ }^{28}$ Los bienes públicos, a diferencia de los privados, poseen ciertas características que hacen problemática la explicación y determinación de los procesos de asignación de los mismos. A grandes rasgos existen dos propiedades fundamentales de estos, por una parte, la no-exclusividad y por otra la indivisibilidad o, lo que es lo mismo, la existencia de oferta conjunta para su consumo. Por exclusión entendemos que, a diferencia de los bienes privados, en los públicos resulta extraordinariamente difícil o costoso excluir a una persona de su consumo. Así, por ejemplo, resulta muy difícil o imposible excluir a una persona de escuchar las emisiones radiales una vez que ella posee una radio. De forma similar, es imposible excluir a una persona del consumo de playa una vez que la sociedad ha establecido que ellas son bienes "comunes", lo que permite a toda persona el ejercicio de ese derecho. Sin perjuicio de que los costos de imponer barreras de entrada al uso de la playa no son altos, la existencia de un derecho impide el establecimiento de mecanismos de exclusión. ¿Por qué? La indivisibilidad se refiere al hecho que el consumo que hace un individuo de él no disminuye la cantidad disponible del bien para otros. El consumo de un bien público es el mismo para todos. Las ondas radiales no se agotan al momento del consumo que cada individuo hace de ellas. El ejercicio del derecho de playa no altera la disponibilidad de playa a ser usada por otros individuos. No obstante, dadas las características físicas de la playa, ella es perfectamente divisible, no obstante el derecho a la misma no lo es y en cuanto tal, a pesar que el consumo de la playa agote las unidades disponibles de playa para otros, el derecho aún subsiste de manera indivisible. Ahora bien, un bien puede ser indivisible aun cuando exclusivo; ejemplos de ellos son las carreteras y puentes. Una vez producidos están a disposición de otros para su consumo, sin embargo, no es costoso excluir a alguien de su consumo, por ejemplo a través de peajes o en el caso de la playa, en ausencia de un derecho común sobre estas. De ello se sigue que la propiedad del bien no determina su naturaleza de bien, sino que altera el dominio legal de la misma, es decir, una carretera o playa pública permite que cualquier persona tenga el derecho al uso de la misma, no obstante ello constituye una ficción legal, pero que en modo alguno impediría que alguien fuera propietario de la misma y cobrara por su uso. En resumen, la indivisibilidad no implica la noexclusividad. La asignación y producción de bienes públicos es problemática por las dificultades existentes de hacer que las personas paguen por ellos. Si ningún individuo pueden ser excluido de los beneficios derivados, digamos del "aire libre de contaminación”, ellos estarán tentados al free-riding, o sea, a obtenerlo sin pagar. Al respecto ver SAMUELSON (1954) 
diseñar un conjunto de políticas que tiendan a llevar los niveles de litigiosidad a los óptimos ${ }^{29}$.

En este sentido, no existe evidencia empírica que demuestre para Chile el nivel óptimo de litigiosidad. La divergencia entre el óptimo privado y el social tiene diversas explicaciones y efectos. Siguiendo el análisis económico del derecho de los litigios ${ }^{30}$, la divergencia entre los incentivos privados y los sociales para usar el sistema judicial, son atribuibles a dos externalidades que producirían la decisión de judicializar un conflicto $^{31}$. En efecto, el nivel privado de litigación puede ser socialmente excesivo e inadecuado, por lo que puede requerir de políticas correctivas que incentiven otras vías de solución de controversias. Así, donde los incentivos privados para usar el sistema judicial sean excesivos, o sea, existan muchos incentivos para recurrir a la justicia, las restricciones en su uso serán deseables y, por el contrario, donde los incentivos privados para usar el sistema judicial sean bajos, se justificaría una política que incentive la litigación hasta aquel punto beneficioso para la sociedad. Estas divergencias en los costos y beneficios llevan, en definitiva, a que las personas demanden más allá de los niveles socialmente adecuados, lo que implica que las políticas en la materia deben orientarse a lograr niveles óptimos de litigación, donde los costos y beneficios, sociales y privados se equiparen, logrando la máxima tutela judicial.

En nuestro sistema, el hecho que el Estado financie completamente al sistema público de tribunales, hace que los potenciales litigantes -al momento de decidir judi-

\footnotetext{
${ }^{29}$ Mery (2003)

30 Ver las obras de SHAVELL (1982), (2003) y (2004a) que son bien sintetizadas por MERY (2003)

31 Por una parte, se produce una externalidad negativa toda vez que una persona cuando decide judicializar un conflicto recurriendo al sistema judicial, no toma en cuenta los costos legales que induce a otros a incurrir. Dicho de otra manera, el demandante cuando decide recurrir a la Justicia, no toma en cuenta, al momento de evaluar si le conviene o no judicializar su conflicto en vez de arreglarlo privadamente, los costos en que deberá incurrir el demandado producto del proceso legal. Por otra parte, se produce una externalidad positiva en el sentido que la decisión de litigar y el desarrollo mismo del juicio, genera beneficios sociales que no son tomados en cuenta por el particular o demandante al momento de decidir recurrir al sistema judicial, como son por ejemplo, los efectos asociados de disuasión que puede producir la sentencia. De estas externalidades se pueden concluir las principales fuentes de esta divergencia entre los incentivos privados y sociales para usar el sistema judicial, a saber, la diferencia entre los costos y beneficios privados y sociales. La primera fuente de divergencia, esto es, la diferencia entre los costos privados y sociales asociados al uso del sistema judicial, se explica por el solo hecho que los costos privados, la mayoría de las veces, son inferiores a los costos sociales del uso del sistema. Cuando una persona decide judicializar un conflicto, no contabiliza los costos en que deberá incurrir el contrario ni los costos del sistema judicial. En otras palabras, al evaluar un arreglo privado no estima como ahorro los costos del contrario ni los costos que habría significado para el sistema judicial haber llevado el asunto a juicio. Ahora bien, la otra fuente de la divergencia dice relación con la diferencia entre los beneficios privados y sociales del uso del sistema judicial. El principal beneficio social que produce el juicio, particularmente la sentencia, es la disuasión de conductas, toda vez que la sentencia entregaría información a la sociedad respecto de las sanciones asociadas a ciertas conductas no deseadas y respecto a la valoración de ciertos derechos. Este beneficio social no es tomado en cuenta por el litigante al momento de evaluar recurrir al sistema judicial. Por su parte, el principal beneficio privado asociado al juicio es la compensación del daño causado o la restauración de un estado de cosas. Como se puede apreciar, el beneficio social es distinto del privado. Donde el primero (beneficio social) sea menor al segundo (beneficio privado) existirán incentivos para litigar.
} 
cializar un conflicto- no contabilicen aquella parte de los costos del litigio que serán de cargo del Estado, por lo que su estimación será incompleta y su decisión, a fin de cuentas, será también incompleta desde un punto de vista social. Si el potencial litigante no internaliza ni tiene a la vista todos los costos que significa recurrir a la justicia estatal, creerá estar consumiendo un bien de un precio más bajo que el real, lo cual se traducirá, en definitiva, en un incentivo a la litigación y en un exceso de demanda ${ }^{32}$.

Como principio general, se podría establecer como mecanismo para corregir y graduar la diferencia entre el nivel privado y social óptimo de litigación, el establecimiento de precios $^{33} \mathrm{u}$ otros mecanismos que aumenten por otras vías el costo de recurrir a los tribunales públicos ${ }^{34}$. Incluso se puede prohibir el ingreso de determinadas causas al sistema público ${ }^{35}$. Por otra parte, si los costos del juicio son una variable fundamental al momento de decidir recurrir o no al sistema judicial, el problema de las costas, o de reglas de distribución de dichos costos, aparece como una cuestión necesaria de examinar. El problema de quién internalizará, en definitiva, los costos del juicio es una cuestión que depende del sistema de costas existente ${ }^{36}$.

Finalmente, no se puede dejar de señalar que uno de los temas que se vinculan estrechamente al uso de precios para la asignación del recurso "justicia” (en la forma de tasas y costas judiciales) en este ámbito, dice relación con los efectos que conlleva su implementación en términos de acceso a la justicia. Así, la primera cuestión es si acaso las tasas constituyen un obstáculo o no al acceso a los tribunales; si acaso se niega el acceso a aquellos que no pueden costear dichas tasas. Para Zuckerman: "Hay

\footnotetext{
32 MerY (2003)

33 Como existe actualmente en muchos países. Ver VARGAS et al. (2001)

${ }^{34}$ Lo anterior permite internalizar los costos del juicio a quienes se benefician con él: como los litigantes no internalizan actualmente la totalidad de los costos del juicio tienden a demandar más allá de lo que sería socialmente óptimo. Además, dado que nadie está dispuesto a financiar el componente de bien público de la justicia, y como a la sociedad le interesa mantener el efecto disuasivo de esta, se hace necesario un subsidio estatal que apunte directamente a resolver un problema de eficiencia en la asignación de recursos. Así, los beneficios sociales de la jurisprudencia y el efecto disuasivo exceden con mucho el beneficio privado de quien recibe la sentencia. Desde ese punto de vista, se justifica un aporte estatal que logre eliminar la brecha entre beneficio privado y social.

35 Un caso paradigmático en este sentido ha sido el sistema de solución de controversias del sistema eléctrico, donde un grupo de "expertos", financiados por las propias empresas, pero designados de acuerdo a un procedimiento legal, solucionan las disputas que se generan entre las empresas vinculadas al sector eléctrico. La Corte Suprema ha dicho que no constituyen "jurisdicción”, pero resuelven controversias jurídicas en forma vinculante, sin posibilidad de ulteriores recursos y sin el derecho de acceder a otra competencia o instancia. Un caso curioso, sui generis, no ortodoxo, que ha dado resultados satisfactorios para todos los interesados (Poder judicial, empresas eléctricas, Gobierno, etc.), no obstante su poca claridad respecto a su "naturaleza jurídica".

${ }^{36}$ Existen, a lo menos, dos reglas de distribución de los costos de litigar, cost allocation rules, o sistemas de costas como se les llama en nuestro sistema legal, a saber, la regla americana y la regla inglesa. Conforme a la regla americana cada parte paga sus costos, mientras que bajo la regla inglesa los costos deben ser cubiertos por la parte perdedora. Es posible advertir todavía, una regla intermedia como la contemplada en nuestro sistema, según la cual los costos del juicio son de cargo de la parte perdedora, salvo que haya tenido "motivos plausibles para litigar". Mery (2003). Desgraciadamente, en nuestro país la regulación y práctica de la institución de las costas deja mucho que desear y dista de cumplir su objetivo.
} 
consenso que en que es injusto denegar el acceso a tribunales en base a la imposición de altas tasas judiciales. Sin embargo, diferentes sistemas emplean diversos métodos para proveer acceso a aquellos que no pueden costear tasas de ingreso al sistema" 37 . Sin embargo, cuando hablamos de los costos del acceso a la justicia debemos considerar dos cuestiones importantes: "En primer lugar, cada sociedad debe hacer una decisión de política pública sobre si el sistema de justicia civil debiera ser financiado primariamente por sus usuarios, los litigantes, a través de tasas judiciales realistas o, alternativamente, si acaso el sistema debiera ser pagado fundamentalmente por los contribuyentes. En segundo lugar, debe ser recordado que bajos costos de litigación incentivan el litigio. A mayor litigio, mayor es el desembolso que deben realizar los contribuyentes para mantener el sistema. Alternativamente, si los recursos no se aumentan correlativamente con el volumen de la litigación, a mayor litigación, mayor será el retraso del sistema. Por consiguiente, la relación costo-acceso es compleja y diferentes sistemas la enfrentan de diversa forma" 38 .

\section{LINEAMIENTOS DE REFORMA A LA JUSTICIA CIVIL}

Luego del diagnóstico presentado y el análisis sobre la naturaleza económica de la justicia civil, se hace necesario, establecer los lineamientos generales de un conjunto de reformas que parecen fundamentales para el éxito de este proceso. Hasta ahora, el debate nacional en torno a la justicia civil ha estado mayoritariamente caracterizado por propuestas de reformas específicas, más que por propuestas globales que resuelvan los problemas de fondo.

\subsection{ESPECIALIZACIÓN DE TRIBUNALES, JUICIOS DE COBRANZAS Y ASUNTOS NO CONTENCIOSOS}

Cuando se habla de especialización, esta se puede referir al contenido del asunto (como la creación de tribunales de quiebra o tribunales de comercio) o a la cuantía de lo reclamado. En esta materia, la experiencia y la evidencia internacional es en extremo útili ${ }^{39}$. En efecto, la creación de tribunales de menor cuantía o su difusión se cuentan entre las reformas judiciales de más éxito ${ }^{40}$. Asimismo, la existencia de tribunales especializados con competencia para entender determinados asuntos -permitiendo los usos

\footnotetext{
37 ZUCKERMAN, 1999, p. 9.

38 ZUCKERMAN, 1999, p. 9.

39 BANCO Mundial (2002) en especial el capítulo 6 sobre Sistema Judicial.

40 En Brasil, por ejemplo, los tribunales de menor cuantía han reducido a la mitad el tiempo que transcurre antes de dictarse el fallo y han ampliado el acceso a la justicia. En Hong Kong, China, transcurren solo cuatro semanas desde que se entabla una acción y la primera audiencia de examen de la causa en el Tribunal de Menor Cuantía. Esos tribunales son muy comunes también en los países industriales. Últimamente el Reino Unido, que ha obtenido con ellos buenos resultados, aumentó a 5.000 libras esterlinas el monto máximo de las demandas que se pueden entablar en esos tribunales. Estos tribunales son también comunes en Australia, Estados Unidos y Japón, y en la Unión Europea se encuentra en estudio una normativa que regule este procedimiento para todos los países miembros. Idem.
} 
modernos superar fácilmente el factor "territorio"- será un claro factor de aumento de eficiencia ${ }^{41}$.

Un aspecto fundamental de la reforma en Chile dice relación con la manera de abordar los juicios de cobranza, así como de los asuntos no contenciosos. Por regla general, ninguno de ellos importa un conflicto que requiera de un dictamen judicial, pero por estar radicados en sede judicial, y particularmente en sede civil, generan niveles de congestión que los actuales tribunales no pueden asumir. Como muestra la evidencia presentada más atrás, la mayoría de las causas en materia contenciosas ingresadas a los tribunales civiles, dice relación con el cobro y ejecución de deudas ciertas (juicios de cobranzas), a las que básicamente les falta la orden de ejecución. Las causas referidas presentan como característica procesal común, el estar sometidas a ciertos trámites no decisionales, más o menos idénticos, lo que significa que, salvo excepciones, la función del tribunal es mecánica y rutinaria. A mayor abundamiento, el alto número de causas por deudas impagas ocasiona atochamiento y demoras con el consecuente perjuicio que ello implica para el acreedor.

En esta materia, como en todas las demás, hay distintas soluciones que se pueden plantear. En primer lugar, y con el objeto de dar una mayor agilidad y efectividad a su tramitación, y dadas las características propias de las cobranzas judiciales, es factible pensar en sacarlas de la esfera de la justicia civil común, reduciendo significativamente la problemática de la "justicia civil". Se podría pensar, por ejemplo, en entregarlas a una nueva forma de "auxiliar de la administración de justicia", creado especialmente para estos efectos, mediante organismos de naturaleza privada o mixta, que -debidamente fiscalizadaspodrían competir entre sí por un mejor servicio. Quienes detenten esta investidura, podrían tener prohibición de realizar otras actividades y serán responsables de velar por los derechos y garantías de ambas partes, pudiendo estar sometidas a un único Tribunal de Cobranzas que haría analógicamente las veces de los tribunales de garantía en materia penal, resguardando el debido proceso y los derechos de las partes. De esta manera, el título ejecutivo se presentaría ante alguno de estos nuevos "órganos", los que serían desig-

${ }^{41}$ Ese tipo de tribunales ha sido establecido para simplificar la cobranza de deudas en varios países, entre ellos Alemania, Japón y los Países Bajos. En Ecuador el establecimiento de tribunales de trabajo ha permitido que se reduzca el tiempo que transcurre hasta que se dicta sentencia. Muchos de esos tribunales especializados hacen hincapié en el arbitraje y la conciliación, de modo que algunos de los resultados positivos que han obtenido pueden deberse a que dan preferencia a métodos alternativos de solución de controversias. Los tribunales especializados también contribuyen a la simplificación y reducen algunos de los procedimientos generales de los tribunales civiles. Por ejemplo, la introducción de un tribunal especializado en comercio en Tanzania redujo el tiempo que transcurre hasta que se dicta sentencia de una media de 22 meses a una media de tres meses. La creación del tribunal de comercio de Tanzania fue resultado de la labor conjunta del Gobierno, la empresa privada y donantes internacionales. Idem.

En Chile, será interesante el análisis que con el tiempo se haga sobre los recién creados juzgados de cobranza en materia laboral y previsional, así como de las causas de su posible éxito o fracaso. Creemos que de funcionar en forma razonablemente satisfactoria, pueden ofrecer un modelo a imitar en el resto de la legislación (principio de simplicidad). Incluso más, en caso de dar buenos resultados -más allá de las infinitas perfecciones de que puedan ser objeto-, podría aumentarse su competencia a otras materias, pasando a convertirse en los "Tribunales de Cobranza" de todos los asuntos. 
nados de común acuerdo por las partes, o por cualquier sistema general, imparcial y ampliamente aceptado (como por ejemplo, la distribución por sorteo). Los honorarios por dicho servicio serán convenidos de común acuerdo por las partes o en su defecto, mediante el establecimiento de un arancel ${ }^{42}$. Naturalmente, y durante muchos años más, deberá pensarse en sistemas complementarios de financiamiento para que personas de menores recursos pueden acceder a esta instancia en forma igualitaria.

En segundo lugar, y tal como se insinuara antes, se podría pensar en utilizar la actual estructura de los tribunales de cobranza en materia laboral, para generar un solo tribunal especializado en materia de cobranza. Aunque esta propuesta tiene el beneficio que conlleva la especialización, no es del todo claro que por sí sola resuelva todos los asuntos de fondo. Si este esquema no toma medidas profundas para resolver otros problemas anexos como la profesionalización de su administración (incluyendo en ello el financiamiento de los tribunales en forma adecuada a sus necesidades y planes de trabajo), el uso de sistemas de información; la simplificación de procedimientos, la externalización de gestiones y asuntos en que se puede aprovechar la eficiencia y competencia de organismos de naturaleza privada (remates, etc.), es posible que en el corto plazo veamos a esta nueva institucionalidad en la misma posición en la que se encuentra actualmente.

En esta materia, también es interesante destacar la experiencia de los juicios monitorios para todas aquellas causas donde existen antecedentes suficientes para presumir la certeza del derecho reclamado. En ellos, cumpliéndose ciertos requisitos establecidos por la ley y verificados por el juez, en vez de darse traslado a la contraparte, se ordena la ejecución. Solo en los casos en que la contraparte se opone fundadamente a ella -que como vimos ocurre en la menor parte de los casos- el proceso deviene en contencioso y se paraliza la ejecución. Este mecanismo ha sido utilizado en forma muy satisfactoria en casi todos los países de Europa continental, aumentando la certeza jurídica sobre el oportuno cumplimiento de las obligaciones ${ }^{43}$.

\footnotetext{
42 José Pedro Silva, Profesor de la Facultad de Derecho Pontificia Universidad Católica, ha sugerido como una posible estrategia de solución el dividir las funciones de los actuales juzgados civiles, de manera de permitir a los jueces concentrarse en las tareas de cognición (bajo la denominación de "Juez de Cognición”). Estos asuntos serán los que impliquen la resolución del conflicto en sus aspectos declarativos principales e incidentales, sea en procedimientos que deban terminar con una sentencia meramente declarativa, de constitución, de condena e incluso ejecutivos (cuaderno principal), así como al fomento y protagonismo efectivo en las vías autocompositivas. Además resolverían a petición de parte o de oficio y vía un recurso especial, cualquier desviación procedimental o abuso cometido por la instancia de ejecución, en especial, en materia de violación de garantías constitucionales. Junto con ello, se debe asignar a los actuales Secretarios de estos mismos Tribunales la función de "Instrucción y Ejecución (Jueces de)", que mantendrían su subordinación jerárquica al Juez Titular o de Cognición y sus funciones subrogatorias, suprimiéndose su rol como Ministros de Fe, los que serían asumidos por el Jefe de la Unidad de Administración de causas.

Esta propuesta nos parece de gran interés, utilidad y pragmatismo, porque permitiría dar un significativo paso adelante sin alterar mayormente las estructuras y prácticas a las que la cultura judicial se ha habituado. Este factor debe ser considerado a la hora de sugerir cualquier reforma, pues corresponde a una limitante real y posiblemente de gran envergadura en el ambiente nacional.

${ }^{43} \mathrm{Al}$ respecto ver el sitio de internet sobre Cooperación en materia de Justicia Civil de la Unión Europea.
} 
Por otra parte, cuando hablamos de los "asuntos no contenciosos", hablamos básicamente gestiones que se realizan ante un tribunal, con el objeto que el juez emita un dictamen en materias donde inicialmente no existe un legítimo contradictor, y a mayor abundamiento, donde lo más probable es que no lo exista jamás. Esta situación se presenta, por ejemplo, en las solicitudes de cambio de nombre, en la constitución de la propiedad minera ( $7 \%$ de los ingresos civiles) ${ }^{44}$ o en la rectificación de una partida de nacimiento. En las situaciones referidas, al no existir un asunto litigioso propiamente tal, el juez -y por extensión el tribunal- se transforma en un mero receptor de antecedentes, asumiendo muchas veces una tarea más administrativa que jurisdiccional, pero con todas las formalidades y resguardos propios de un sistema procesal decimonónico. En efecto, en la mayoría de los procesos referidos, los servicios públicos informan sobre la gestión determinada, e indican si ella es o no procedente. Así, por ejemplo, cuando se solicita una rectificación de una partida de nacimiento, los antecedentes son remitidos por el juez al Servicio del Registro Civil para que este informe si procede o no la gestión que se solicita.

En este contexto, parece razonable traspasar la competencia administrativa que actualmente poseen los tribunales, a las instituciones que en la práctica deciden acerca del derecho que se pretende, reservando la intervención del juez solo a aquellos casos en que haya un interés público relevante envuelto, como por ejemplo, en la constitución de algunos títulos de dominio, o cuando existan diferencias con el referido servicio público o con terceros. De este modo, en el evento de que el trámite de alguna de estas gestiones se transforme en un asunto contencioso, como cuando una persona reclama el reconocimiento de la calidad de heredero que le ha sido desconocida, la instancia competente siempre deberá ser la judicial. Creemos que en el ambiente nacional existe amplio consenso respecto a lo medular de esta situación y a la forma de enfrentarla. Más allá de las problemáticas de implementación y transición que en muchos casos puedan haberse suscitado, un ejemplo de un avance en este sentido ha sido el traspaso al Registro Civil del trámite llamado "posesión efectiva" de las succiones intestadas, antes realizados por los Tribunales Civiles.

\subsection{MeCANismos alternativos de RESOlución DE CONFLiCTOS}

Cuando se enfrenta la manera de alcanzar una mejor administración de justicia, al menos se deben analizar dos cuestiones. Convenir cuál es el mecanismo que mejor garantiza una administración de justicia adecuada, y determinar, desde un punto de vista económico, su modalidad más eficiente ${ }^{45}$. Adicionalmente, es también evidente que se

\footnotetext{
${ }^{4}$ Una propuesta de solución para esta problemática ha sido planteada por el profesor Francisco Javier Leturia, cuyo resumen se encuentra en el proyecto de tesis presentado por el alumno Pablo Trigo en la Facultad de Derecho de la Pontificia Universidad Católica de Chile, y que actualmente se encuentra en elaboración.

45 Si la reducción del costo del sistema público disminuye simultáneamente la protección de los derechos de las personas (ya que si al reducir los costos del sistema judicial no se reduce la protección de los derechos de las personas, ello implica que el sistema es ineficiente). PEÑA (1994).
} 
requiere de una respuesta judicial rápida. La oportunidad es una característica importante en la solución de materias civiles y comerciales ${ }^{46}$.

Por ello, la búsqueda de los llamados mecanismos alternativos de resolución de conflictos está relacionada directamente con las cuestiones planteadas previamente ${ }^{47}$. De hecho, no será difícil coincidir en que su fortalecimiento debiera implicar sacar del ámbito de los tribunales asuntos que pueden ser resueltos en forma más conveniente, eficiente y oportuna en instancias institucionales diferentes, o incorrectamente llamadas "alternativas" 48 . Además, por la especialización y el tiempo que pueden dedicar a cada caso, asegura procesos y sentencias más justas y de mejor calidad, permitiendo, de paso, descongestionar nuestro colapsado sistema judicial.

La experiencia internacional en esta materia es relevante ${ }^{49}$, y muestra que la presencia de métodos alternativos de solución de controversias también puede reducir las oportunidades de corrupción ${ }^{50}$.

46 Para ZuCKerman: "El tiempo puede erosionar la utilidad de una decisión independiente de su rectitud. Con el paso del tiempo llegará un punto más allá del cual el retraso lesiona la utilidad práctica de la decisión. Una decisión entre dos litigantes puede aplicar correctamente el derecho a los hechos del caso y sin embargo ser pronunciada muy tarde para la utilidad práctica del litigante ganador. (...) Se sigue que una decisión puede ser injusta no porque es incorrecta en los hechos o el derecho, pero porque llega en forma extemporánea a resolver la cuestión. (...) Nos podemos referir a este aspecto del retraso como el efecto incremental del retraso, por el cual se considera la desutilidad incremental de un remedio en el curso del tiempo (...) Así, la justicia demanda que las decisiones sean pronunciadas en un tiempo cuando todavía puedan ser remedio para lo que se alega o, si lo que se alega no ha ocurrido todavía, cuando esto pueda ser prevenido a tiempo". (ZUCKERMAN, 1999, pp. 6-7).

47 Aunque no es materia de este trabajo, no queremos dejar de reparar en un asunto lingüístico de gran relevancia e interés sociocultural. Existiendo consenso en que los "métodos alternativos" son funcionalmente equivalentes al sistema judicial, no se ve la razón para llamarlos de esa manera. Más bien podría llamárseles "mecanismos naturales u ordinarios de solución de conflictos" o simplemente "mecanismos de solución de controversias", dejando al mundo de los litigios en tribunales públicos en la dimensión excepcional y residual que les corresponde y que tienen en la realidad, si miramos la conflictividad humana globalmente. Hecha ya este comentario, y siendo el término utilizado mayoritariamente (al igual que la sigla inglesa ADR), por razones comunicativas y de focalización, mantendremos la expresión en adelante.

${ }^{48}$ Ver nota anterior.

49 "En los países en desarrollo con sistemas judiciales ineficaces, los procedimientos legales establecidos para la solución de controversias se pueden reemplazar por otros mecanismos, desde procedimientos informales de mediación basados en normas hasta tribunales arbitrales formales basados en un proceso legal simplificado. La administración de los sistemas puede estar a cargo de las comunidades o del Estado. A medida que los sistemas formales se desarrollan, aumenta la utilización de los tribunales convencionales, lo que significa que un número proporcionalmente mayor de controversias se resuelve en este tipo de tribunales. Por último, a medida que los tribunales adquieren mayor eficiencia y sus fallos resultan suficientemente previsibles, la concertación de acuerdos extrajudiciales puede aumentar en relación con el número de demandas judiciales presentadas". (BANCO MUNDIAL, 2002, p. 126). Esta experiencia también muestra que los métodos alternativos de solución de conflictos, sean estos voluntarios o no, dan mejor resultado cuando los tribunales son eficientes. En otras palabras, las partes en un conflicto tienen un incentivo para llegar a un arreglo cuando saben cuál será el fallo del tribunal: los tribunales complementan a los otros sistemas. Sin embargo, en muchos países ello no es así, aumentando la "independencia” de los sistemas alternativos de solución de conflictos.

También se debe considerar que los resultados de los métodos alternativos de solución de controversias de carácter obligatorios han sido relativos y pueden producir consecuencias no deseadas. Ello se debe en parte 
A la hora de establecer el uso de estos mecanismos, parece clave distinguir entre aquellas materias cuya naturaza hace recomendable el uso de estos y aquellas que no; como asimismo el tipo de mecanismo a utilizar. En efecto, cuando se busca resolver conflictos en que necesariamente existe un ganador y un perdedor respecto de la adjudicación de un derecho, el mecanismo alternativo de resolución de conflictos más acorde sería el arbitraje. Por otro lado, cuando un conflicto no tiene un componente "adversarial" o no es un "juego de suma cero" (por ejemplo, divorcio, alimentos, problemas de vecindad, negociaciones colectivas laborales, etc.) el mecanismo alternativo tendrá más bien un carácter de complementariedad, tal como es la mediación (o un árbitro especializado y que considere y sepa manejar estas variables).

Además, al peso de la cultura y de las prácticas jurídicas usuales, parece obvio que la existencia de tribunales estatales "gratuitos" no favorece la solución de conflictos mediante un esquema alternativo, sea a través de un arbitraje o una mediación pagada (una suerte de "competencia desleal"). Ante este escenario, la razón de su existencia y utilización en la actualidad, entonces, solo puede ser que el producto que estos sistemas entregan no es el mismo que el que entrega el sistema público de tribunales. Mientras esta situación se mantenga, constituirán la alternativa más atractiva para la tramitación de un vasto conjunto de asuntos (incluida la litigación instrumental), en perjuicio de los métodos alternativos, distorsionando un sistema eficiente de asignación de recursos en el sector. Con todo, aun cobrándose por los servicios judiciales, no parece posible que ellos compitan exactamente de igual a igual por las causas judiciales en un mercado transparente de resolución de conflictos que integre también a árbitros y mediadores, por las características específicas que muchas veces tienen estos últimos (acuerdos de fallos privados, derecho aplicable, sentencias sin fundamentos, y en general cualquier flexibili-

al hecho de que los litigantes están obligados por las decisiones arbitrales. Por ejemplo, pueden recurrir a los tribunales después de un arbitraje obligatorio. Tanto los particulares como el Estado pueden establecer sistemas de arbitraje voluntario. En Estados Unidos, por ejemplo, los tribunales con los procedimientos más intensivos de arreglo entre las partes tienden a ser los que más tardan en llegar a una decisión. Ni el tiempo de tramitación ni la productividad judicial mejoran con la existencia de extensos programas de solución de diferencias. La remisión de las causas a arbitraje obligatorio no influye mayormente en el tiempo que se tarda en llegar a una decisión, ni en las horas de trabajo ni en la satisfacción de los abogados, así como tampoco tiene un efecto decisivo en las opiniones de los abogados sobre la imparcialidad. En algunos programas de mediación - por ejemplo los de Japón y de algunos países de América Latina- el mediador es también el juez. Esta situación puede ser injusta desde el punto de vista procesal, ya que el juez puede presionar a las partes para que lleguen a un acuerdo. Las partes tendrán temor a expresarse con franqueza ante el mismo funcionario que más adelante dictará un fallo que les concierne. BANCO MUNDiAL (2002) p. 127.

${ }^{50}$ Un sistema judicial que compite con otras instituciones tiene menos posibilidades de extraer rentas de los litigantes. Los miembros más pobres de la sociedad y las empresas que no están afiliadas a grandes consorcios comerciales son los que tienen más probabilidades de resultar perjudicados por la inaccesibilidad, la corrupción o la ineficiencia de los tribunales. La evidencia indica que la mejor manera de lograr que las sentencias se cumplan es que todas las partes conozcan la forma en que se llega a las decisiones. La legitimidad de la mediación depende en gran parte de los incentivos que tengan los agentes para cumplir las decisiones del foro. En la mayoría de los países, esos incentivos son las normas de la sociedad, la perspectiva de que se repitan las instancias de mediación, o la amenaza de acción judicial. BANCO MUNDIAL (2002) p. 127. 
dad que solo puedan ofrecer estos sistemas). Así, el sistema de tribunales públicos operará como una instancia residual a la que las partes siempre podrán acudir cuando no esté disponible la otra modalidad. Se asegura así que todos los conflictos tengan realmente una sede adecuada donde obtener su resolución. En el Chile actual, cabe señalar que al menos para un segmento de causas (relaciones comerciales e interempresas principalmente) el arbitraje ha pasado a convertirse en un sistema normalmente utilizado y bastante competitivo frente los propios tribunales ${ }^{51}$, y pese a los mayores costos que implica, la tendencia que muestra es de crecimiento y mayor uso.

Por otro lado, existe una serie de consideraciones que deben tenerse presente a la hora de diseñar políticas públicas que promueven el uso de mecanismos alternativos de resolución de conflictos y en particular el arbitraje. En este sentido, en el sistema actual, la decisión de demandar ante la justicia arbitral (y la de defenderse) solo incorpora los costos y beneficios que ello reporta para cada actor, sin que influyan en tal decisión los beneficios que el resto de la comunidad recibe al resolverse adecuadamente los litigios. Así, en la medida en que un fallo genera externalidades positivas que son deseables por la sociedad toda, cabe pensar algún tipo de aporte estatal. Pero hasta ahora se ha considerado como punto de partida del arbitraje que constituye un servicio privado cuyo costo lo soportan las partes litigantes. Ello también cobra importancia si no se cuenta con ningún sistema para conocer, difundir y socializar el contenido de las sentencias arbitrales (opción atractiva que ciertamente podría adoptarse y justificarse), lo que limita sus efectos más allá de las partes que en esos juicios intervienen. En segundo lugar, solo pueden concurrir a litigar ante árbitros quienes posean medios suficientes para solventar tanto los costos del arbitraje como los correspondientes a los honorarios de sus abogados y otros gastos relacionados. No existe en este caso la posibilidad de acceder ni al gasto público de justicia, que opera generalizadamente, tratándose de los tribunales, ni al subsidio específico que se suma al anterior en favor de las personas pobres y que cubre los otros costos de litigar. En esta materia, cabe pensar un subsidio a la demanda para que personas pobres puedan acceder a un árbitro como alternativa de resolución de una controversia, pero deberá implementarse junto a ello un buen sistemas de fiscalización y prevención de fraudes.

\subsection{REFORMAS DE CARÁCTER PROCEDIMENTAL}

Para Chile, las razones que debieran conducir a una nueva estructura del proceso y de sus respectivas etapas son muchas ${ }^{52}$. Por ejemplo, al igual que en el nuevo proceso penal, es conveniente que el juicio se inicie prontamente con la recopilación de pruebas y antecedentes, lo que permitirá concretar la discusión y centrar el debate en aquellas

\footnotetext{
${ }^{51}$ VARGAS et al. (2001).

52 Uno de los aspectos relevantes que se puede destacar del derecho comparado y particularmente de la experiencia uruguaya es contar con un proceso civil que esté caracterizado por la inmediación, economíaceleridad, concentración-eventualidad, publicidad, buena fe-lealtad procesal, dirección del proceso por el juez, igualdad procesal e impulso procesal de oficio. Exposición del profesor uruguayo Santiago Pereira en el Seminario "Justicia Civil; Una Reforma Pendiente" (2004).
} 
materias verdaderamente controvertidas y conociendo a priori las fortalezas y debilidades de cada pretensión. Ello facilitará el trabajo del juez y aumentará las posibilidades de solucionar el acuerdo por vías voluntarias (transacción, conciliación, entre otras). De esta manera, es muy probable que un sistema que anticipe la presentación de la prueba a etapas anteriores, facilite la salida del juicio por medio de la conciliación. Es evidente que si las partes y el juez conocen con exactitud la prueba que se utilizará en el litigio, y por lo mismo, las fortalezas y debilidades de sus pretensiones y el probable resultado de la sentencia, la posibilidad de llegar a un acuerdo son mayores.

Con la estructura actual, las partes deben realizar sus alegaciones sin saber los antecedentes de hecho del asunto litigioso ${ }^{53}$. Asimismo, es deseable que el juez se entere

53 Puede ser tentador decir que los sistemas con "discovery obligatorio" realizan una mayor contribución a la rectitud de las decisiones, porque el discovery tiende a entregar mayor evidencia relevante y por consiguiente lleva a una mayor precisión factual en las sentencias. Pero dicha conclusión sería superficial porque el discovery tiene sus propias desventajas. Existe una considerable preocupación en los sistemas AngloAmericanos sobre las implicancias negativas en términos de costo del discovery. En una significativa proporción de casos en que el discovery es utilizado en forma seria, los costos del proceso exceden los beneficios. Altos costos de litigación afectan en forma adversa el acceso a la justicia disuadiendo la entrada de litigantes de pocos recursos. Por consiguiente, una comparación entre los sistemas Anglo-Americano y continental debe considerar no solo la dimensión de rectitud en la decisión del discovery sino también la dimensión de costos. Cuando ambas dimensiones son consideradas, podríamos llegar a concluir que lo que los sistemas continentales pierden en rectitud, lo ganan aumentando en acceso a la justicia. A mayor abundamiento, la comparación entre diversos sistemas judiciales y procesales llama por tanto a un enfoque de carácter integral; esto es, la evaluación de los sistemas como un todo. Cada sistema individualmente considerado, debe ser juzgado en relación a diversos criterios (por ejemplo, rectitud de las decisiones, tiempo y costo). Sin embargo, debemos ser claros respecto de las limitaciones del enfoque comparado: una investigación multidimensional puede revelar las fortalezas y debilidades de los sistemas individualmente considerados, pero no necesariamente dirá cuál de los sistemas es el mejor: "Solo porque un procedimiento entrega mayor peso relativo a la rectitud de las decisiones no implica que sea mejor que un sistema distinto que sacrifica la rectitud por entregar decisiones más rápidas y en el tiempo adecuado. Como hemos visto, el solo hecho que el discovery sea un buen método para obtener la verdad no es un argumento concluyente para importar dicha figura a un sistema que prefiere mantener los costos bajos. Cada sistema procesal tiene sus preferencias cuando llega la hora de tomar decisiones entre las diferentes dimensiones de la justicia". (ZUCKERMAN, 1999, p. 10-11).

Vinculado a lo anterior podemos hacer referencia a la propuesta de Jorge Vial, profesor de la Facultad de Derecho UC, quien ha propuesto adoptar un nuevo proceso con tres etapas. La primera consistiría en una etapa de investigación de los hechos llamada Discovery en el derecho procesal civil norteamericano. Esta etapa se inicia con una demanda muy breve en que el demandante expresa someramente la acción que se intentará y quiénes serán las partes en el juicio. Las partes irán solicitando "medidas prejudiciales probatorias o preparatorias de la demanda" a un juez de control que las concederá o denegará según las estime conducentes a la preparación del juicio. Las pruebas se rinden privadamente, usualmente en las oficinas de los abogados, con la presencia de un oficial de la corte que, en este caso, puede ser un receptor judicial. Si durante la investigación, que tiene un plazo máximo legal, alguna de las partes estima que no hay bases para continuar, se puede proceder a desestimar la demanda sumariamente, resolución que es apelable. Esta etapa tiene varias ventajas. El Estado se ahorra gran cantidad de recursos en juicios que luego no tienen destino. Las partes llegan al eventual juicio conociendo bien sus fortalezas y debilidades. Usualmente se producen avenimientos sobre la base de la evidencia. La disputa se depura antes de llegar al Tribunal.

En los casos en que se cumple el plazo legal de la etapa de investigación, y no ha terminado la causa por una salida alternativa o por solicitud de desestimarla, el demandante debe presentar ahora una demanda 
de los hechos y de la prueba de la manera más directa posible, sancionándose incluso con la nulidad algunas diligencias probatorias realizadas sin su presencia ${ }^{54}$. En el mismo ámbito, existe consenso en que se debe flexibilizar el sistema de medios de prueba, eliminándose la taxatividad, y permitiéndose, además, su incorporación al proceso en cualquier forma razonable, siempre que ella garantice su fidelidad (autenticidad) y conservación. Además, salvo los casos en que la formalidad sea un requisito de validez o existencia, la prueba hecha constar en el proceso, debe ser apreciada bajo el criterio de la sana crítica, privilegiándose de esta manera la búsqueda de la verdad real por sobre la llamada verdad jurídica o procesal. Bajo este esquema, la correcta fundamentación de la sentencia y la adecuada exposición de los criterios utilizados en la apreciación de la prueba, resulta fundamental. Así, la apreciación de la prueba incorrecta o mal fundada, podrá ser causal de nulidad de la sentencia.

Del mismo modo, deben ampliarse las facultades del tribunal para ordenar medidas para mejor resolver, siempre que ellas sean fundadas y de cargo de las partes, sin perjuicio de lo que posteriormente se resuelva en materia de costas. Este aumento de las facultades para ordenar medidas para mejor resolver, coincide también con el rol activo que corresponderá asumir al juez en la búsqueda de la verdad y la consecución de la justicia. Lo mismo podrá decirse de las potestades cautelares e innovativas en general.

Asimismo, un nuevo procedimiento civil debiera restringir al máximo la interposición de incidentes y reclamaciones que desvíen o dilaten innecesariamente el proceso, sancionando eficazmente el abuso que de ellos hacen las partes y sus abogados, buscando postergar el cumplimiento de una resolución que suponen les será desfavorable ${ }^{55}$.

Además, debe racionalizarse la utilización de recursos procesales, evitando la suspensión del procedimiento y de la ejecución, así como de toda reclamación que carezca de fundamento ${ }^{56}$.

detallada. El juez de control examina la evidencia y la demanda y puede desestimar la demanda de inmediato por falta de fundamento, lo que es apelable, o darle curso, caso en el que deberá citar a una audiencia de preparación del juicio que es oral. El juicio es oral ante un tribunal que puede ser colegiado en un esquema similar al juicio penal moderno. La idea es que los menos casos lleguen a juicio oral, ya sea porque el sistema privilegia los avenimientos, o el juez de control desecha la demanda durante o al término de la etapa de investigación, o se crean procedimientos sumarios alternativos al juicio oral para ciertos casos. Presentación de Jorge Vial en el Seminario “Justicia Civil: Una Reforma Pendiente” (2004).

${ }^{54}$ Mecanismo propuesto en el Proyecto de Código Procesal Civil Modelo para Iberoamérica (salvo para la prueba a rendirse fuera del territorio jurisdiccional).

$55 \mathrm{Al}$ respecto, se ha propuesto aumentar ostensiblemente el monto de la multa; hacer solidariamente responsable al abogado y a la parte de su pago (tal como ocurría hasta hace poco con las costas cuando era rechazado un recurso de casación); sancionar disciplinariamente a los abogados que interpongan incidentes manifiestamente infundados o que hayan perdido más de dos incidentes formulados por ellos; exigir que los tribunales hagan uso de su facultad legal de rechazar de plano los incidentes que no tengan conexión alguna con el asunto en litigio.

56 De hecho en la investigación efectuada por alumnos de la Facultad de Derecho de la Universidad Católica se detectó que menos de un $4 \%$ de las causas iniciadas ingresa a una segunda Instancia. Ver nota 13. También al respecto, y particularmente sobre las posibilidades de limitar el recurso de apelación, ver la tesis de grado del alumno Oliver Mahn de la Facultad de Derecho de la Pontificia Universidad Católica, dirigida por el profesor Francisco Javier Leturia. 
Otro elemento dice relación con el exceso de procedimientos existentes, lo que aumenta excesivamente el poder de los abogados frente a los clientes, facilita la posibilidad de perder derechos por razones meramente procedimentales, y no tiene, en el fondo, ningún fundamento para mantenerse. El ejemplo uruguayo en este sentido es ejemplar: existen solo tres procedimientos: el ordinario, el sumario y el monitorio o de ejecución ${ }^{57}$.

La reforma procedimental parece estrechamente vinculada a otro de los grandes defectos de nuestro sistema jurídico de raigambre continental o de código: el apego al formalismo por parte de los jueces; que muchas veces, aunque parezca lo contrario, ofrecen una coartada muy adecuada para la arbitrariedad ${ }^{58}$.

Finalmente, creemos importante señalar que el correcto diseño de las instituciones procesales debe al mismo tiempo compatibilizar una razonable protección de nuestros derechos, con el nivel general de recursos que posee la sociedad, y con los otros servicios públicos que la comunidad debe proveer, y es, por lo mismo, esencialmente dinámico ${ }^{59}$. Este enfoque también lo encontramos en las obras de Posner y Shavell, desde la perspectiva del análisis económico del derecho ${ }^{60}$. Para Zuckerman: "Una vez que se ha aceptado que la asignación de recursos para la justicia civil no es absoluta ni ilimitada, también debemos aceptar que la elección de procedimientos también implica un cierto grado de renuncia. Se sigue que, en diseño del sistema procesal, el legislativo tiene un margen considerable de elección entre diversas alternativas que logren equilibrar rectitud de las decisiones y los costos de dicho sistema. (...) Porque es legítimo preguntarse si acaso el contribuyente se encuentra obligado a invertir vastas sumas de dinero en la administración de la justicia civil, cuando la justicia se puede comprar en forma más barata, aunque sea menos precisa" 61

57 La reforma a la Ley de Enjuiciamiento Española del 2000 también avanza en el mismo sentido.

58 En este sentido, Pasara sostiene: "No es cierto que el apego a las formas y a la letra de la ley que traducen en su actuación la mayor parte de nuestros funcionarios judiciales, provenga de una obligación legal inevitable, como pretenden exculpatoriamente algunos voceros de la judicatura. Se trata de un componente de la cultura jurídica prevaleciente, dotado de una gran fortaleza para determinar prácticas". (PASARA, 1997, p. 162). Por su parte Carlos Peña establece que el problema consiste en que los jueces aparecen más comprometidos con los medios que con los fines del sistema legal. PEÑA (1999).

Por su parte, Enrique Barros ha observado que recurrir formalistamente a la ley puede esconder algo más grave: "Hay decadencia en la forma de fundamentar las sentencias y se ha expandido la inseguridad acerca de los criterios de decisión. La causa, en contra de lo que se escucha, hay que buscarla más en el subjetivismo judicial que en el formalismo. El legalismo formalista es más bien una excusa, que persigue distraer de la pregunta por la responsabilidad judicial. La actitud reticente de los tribunales en materia de derechos fundamentales, por ejemplo, ha sido justificada con el argumento de que a los jueces solo les corresponde aplicar la ley. Sin embargo, puede comprobarse que el problema no deriva de una rígida e inexorable técnica profesional de nuestros jueces superiores. Basta contrastar los criterios estrictísimos de interpretación seguidos en casos de abusos de poder público, con la liviandad con que se recurre a criterios francamente discrecionales al fallar recursos de queja". (BARROS citado por PASARA, 1997, pp. 162-63).

59 A modo de ejemplo citaremos a un autor que ha contribuido a difundir y explicitar esta máxima de buen gobierno y sentido común DWORKIN (1985), en especial el capítulo 3.

${ }^{60}$ Especialmente ver POSNER (2000) y SHAVELL (2004a).

61 ZUCKERMAN, 1999, pp. 8-9. 
Si se analiza la experiencia de reformas procedimentales desde una óptica comparada, una de las conclusiones principales dice relación con que la simplificación de los elementos procesales está vinculada a un aumento de la eficiencia del sistema judicial, pues se reducen tanto los costos como los retrasos ${ }^{62}$. En muchos países, la complejidad de los procedimientos reduce la eficiencia judicial, lo que resulta más grave y notorio en países en desarrollo ${ }^{63}$, dado que tienen un menor nivel de capacidad administrativa y capital humano, un mayor nivel inicial de corrupción y un menor número de instituciones complementarias. La complejidad de los procedimientos también facilita la corrupción si no hay transparencia. Cuando existen instituciones de apoyo, capital humano y recursos, la complejidad tiene un costo menor en términos de eficiencia. Los procedimientos transparentes, que permiten a los jueces cierto grado de innovación y experimentación pueden contribuir a incrementar la eficiencia judicial ${ }^{64}$; más aún, la simplificación del sistema mediante el cual se determina el procedimiento judicial mismo puede ser beneficiosa ${ }^{65}$. Además, desde un punto de vista cualitativo, la racionalización procesal afecta no solo a los costos y a la rapidez de los procesos, sino también a su imparciali$\mathrm{dad}^{66}$

62 En este sentido, "un factor comúnmente vinculado a la ineficiencia en los países de tradición jurídica romanista es el predominio de los procedimientos escritos sobre los procedimientos orales. Esto es especialmente importante en América Latina. El cambio a procedimientos orales ha producido resultados positivos en Italia, Paraguay y Uruguay. (...) La simplificación de los procedimientos tiende a tener efectos positivos en la eficiencia, ya que la mayor complejidad de los procedimientos reduce la transparencia y la responsabilidad, y aumenta la capacidad de los funcionarios corruptos de recurrir al soborno. La simplificación de los procedimientos tiende a reducir los plazos y los costos y a aumentar la satisfacción de los litigantes (por ejemplo, el procedimiento simplificado de los tribunales de menor cuantía británicos, o los jueces de paz en Perú)". (BAnCo Mundial, 2002, pp. 127-28).

${ }^{63}$ Sin embargo, no todo intento de simplificación da resultado. En este sentido: "es necesario adaptar el proceso a las circunstancias del país, razón por la cual se requiere cierto grado de experimentación (...) Otro factor que limita la capacidad de la reforma procesal de aumentar la eficiencia del sistema judicial es la propia ley. Si las normas sustantivas son poco claras y las demás instituciones son débiles, la reforma de los procedimientos solo podrá mejorar la eficiencia en forma limitada (...) La simplificación sustantiva también puede ser la causa de las mejoras de la eficiencia a que se hace referencia en los estudios sobre los tribunales de menor cuantía". (BANCO Mundial, 2002, p. 128).

64 BANCO Mundial (2002) p. 119.

65 Así, "Si es necesario que toda modificación procesal sea aprobada por el Legislativo, la experimentación y la innovación se hacen difíciles. Las facultades del Legislativo para determinar la organización y las normas de procedimiento de los tribunales podrían delegarse en parte en el Poder Judicial; esa medida ha resultado beneficiosa en el Uruguay. O bien, el Legislativo podría delegar parcialmente esas facultades en tribunales individuales a fin de alentar una mayor flexibilidad, como se ha hecho en el Reino Unido, donde los jueces que se ocupan de las causas de menor cuantía están facultados para aprobar cualquier procedimiento que estimen justo y eficiente". Sin embargo, mayores facultades para los jueces requiere de mecanismos efectivos que sirvan como controles y contrapesos: "La delegación de esas facultades en los jueces da mejor resultado cuando también existen medidas establecidas para aumentar la responsabilidad”. (BANCO MUNDIAL, 2002, p. 128).

66 De la evidencia disponible se desprende que, en los sistemas judiciales que se basan excesivamente en procedimientos escritos, la introducción de procedimientos orales tiende a simplificar los juicios y a hacerlos más rápidos y mas baratos, sin que haya una pérdida apreciable de imparcialidad, ya que el juez tiene contacto directo con las declaraciones. La imparcialidad, en el contexto del sistema judicial, puede interpretarse como la aplicación sistemática de la ley con independencia de la naturaleza de las partes 


\subsection{JURISPRUDENCIA: SENTENCIAS JUDICIALES CON VALOR SOCIAL}

Un factor determinante para que el sistema judicial genere externalidades positivas en la ciudadanía es que sea predecible. Solo si las personas que no han participado en un pleito piensan, con algún grado de fundamento probable, que los criterios con que se falló en él pueden serles aplicables en una situación similar, los tomarán en cuenta en sus razonamientos y actuaciones. En cambio, si las sentencias judiciales tienen un grado alto de aleatoriedad, si su contenido puede variar entre un caso y otro similar, los sujetos racionalmente no pueden adecuar su conducta al derecho, pues este es cambiante y se verán alentados a asumir conductas oportunistas frente a los procesos judiciales.

Desde el punto de vista del derecho comparado, la mayor parte de las reglas del derecho común (common law) han sido elaboradas por jueces y no son estatutarias; y aun en los campos estatutarios, muchas de las reglas específicas de la obligación legal son interpretaciones judiciales del lenguaje estatutario general. Las reglas elaboradas por los jueces son resultado de la práctica de decidir de acuerdo con el precedente (stare decisis $)^{67}$. Cuando se decide un caso, se constituye un precedente, es decir, una razón para decidir un caso similar en la misma forma. Mientras que un precedente aislado es frágil y transmite poca información sobre el funcionamiento del sistema legal (algo que simplemente puede ser señalado, omitido o rechazado por un tribunal del mismo nivel o superior, o incluso por el mismo tribunal en una ocasión posterior), la acumulación de precedentes sobre una misma cuestión, podría crear una regla de derecho dotada incluso de más fuerza que algunas reglas estatutaria explícitas ${ }^{68}$.

Desde la perspectiva económica, los precedentes tienen un importante efecto en el nivel de litigiosidad. El punto de partida es asumir que el arreglo extrajudicial es más barato y preferible al litigio. Por tanto, si cada uno de los disputantes espera que le vaya

involucradas. La impresión que se tiene de la imparcialidad de las normas o leyes varía según los valores de cada sociedad y de su estructura política y social. En este sentido, la falta de imparcialidad obedecería a dos causas principales: "La primera se produce cuando las decisiones judiciales no son independientes de las decisiones políticas, y cuando los tribunales no pueden garantizar que los demás poderes públicos acatarán la ley. En segundo lugar, también puede haber falta de imparcialidad si las partes son poderosas entidades privadas que influyen en las decisiones del tribunal”. (BANCO MUNDiAL, 2002, p. 119). Ciertamente el asunto es más complejo, y siendo también necesarias considerar, entre otros factores, la confianza que la ciudadanía - los justiciables, los eventuales usuarios- tengan en que el tribunal que los juzgará respetará la ley, el debido proceso y las garantías constitucionales (sin perjuicio de la justicia o mérito de esta apreciación).

67 Desde el punto de vista económico, el conjunto de precedentes de un área es un acervo de bienes de capital; específicamente, un acervo de conocimientos que durante muchos años genera servicios a los disputantes potenciales mediante la información acerca de las obligaciones legales. Los bienes de capital se deprecian; el valor de los servicios que brindan disminuye con el tiempo. Ello puede ser consecuencia, en el caso de la información (precedentes) de que sea obsoleta. Por supuesto, el que un bien de capital se deprecie no significa que deba reducirse el acervo de capital del que forma parte. Eso dependerá de la rapidez con que se reemplacen los bienes de capital. A medida que los viejos precedentes se vuelven obsoletos, hasta que finalmente dejan de ser parte del acervo de precedentes que se pueden usar, nuevos precedentes se agregan al acervo mediante el litigio. POSNer (2000) p. 506. Por otro lado, Landes y Posner, han calculado la tasa de depreciación de los precedentes, que en el caso americano llegaría al 4 a $5 \%$ anual. LANDES y POSNER (1976)

68 Posner (2000) p. 506. 
mejor en el litigio, será poco probable que se pongan de acuerdo para arreglarse. La incertidumbre es una condición necesaria para tal divergencia de las expectativas. Puede ser de hecho o legal, pero solo la incertidumbre legal es importante aquí. Si la incertidumbre es grande, habrá mucho litigio, incluido el nivel de la apelación (si la posibilidad de que unos jueces reviertan el resultado de otros inferiores es alta). Finalmente, con pocos precedentes nuevos producidos, la incertidumbre legal aumentará a medida que los precedentes antiguos se deprecian (porque son menos informativos en un ambiente modificado), y esta incertidumbre generará una nueva oleada de litigios y por ende una mayor producción de precedentes ${ }^{69}$.

En otras palabras, cuando a lo largo del tiempo la jurisprudencia es relativamente estable y coherente, ella se constituye en una forma de "capital social": las personas saben con anticipación qué esperar de los tribunales y pueden incorporar dicha información en sus decisiones. Por el contrario, si los agentes involucrados no pueden anticipar razonablemente cuál será la línea de acción de los tribunales, dicha incertidumbre se traducirá en múltiples costos que dificultarán las relaciones entre los actores sociales. Así, si una misma norma tiene distintas interpretaciones y alcances, cuando se repitan situaciones similares en el futuro, siempre terminarán en juicio, porque ambas partes tendrán la expectativa de que el tribunal los favorezca. En ese caso, todo el costo que significó el primer juicio no constituye ningún aporte a los otros casos acaecidos posteriormente: el país y las personas incurren entonces una y otra vez en costos judiciales para casos que son prácticamente idénticos, generándose, además, incertidumbre e inseguridad. Incluso, y desde la óptica de la Teoría de Juegos y el Derecho, la posibilidad de acuerdo entre las partes disminuye si las probabilidades de ganar son similares para uno y otro: ¿por qué ceder si se espera ganar $?^{70}$ En cambio, si la jurisprudencia fuera relativamente estable, bastaría con algunas resoluciones en la materia para que el mercado captara dicha información y la aprovechara: menos juicios serían necesarios si con anticipación sabemos cuál es el sentido de la ley y quién tiene mayor probabilidad de ganar. El costo de litigar una y otra vez por causas similares se reduce a unos pocos litigios que proveen información para los demás casos ${ }^{71}$. De esta manera, el sistema no solo se hace más costoso por la cantidad juicios, sino también por la cantidad de precauciones que se deben tomar para evitar ser estafado, engañado, etc. ${ }^{72}$.

\footnotetext{
${ }^{69}$ Sin embargo, dado que es el propio litigio el que genera precedentes, sobre todo al nivel de la apelación, el incremento del litigio generará una reducción de la incertidumbre legal. Por tanto, la cantidad de litigio bajará -en un modelo teórico y con la ficción "ceteris paribus"- en el periodo siguiente. POSNER (2000) p. 508.

70 BAIRD et al. (1994)

${ }^{71} \mathrm{Al}$ respecto ver HUA y SPIER (2005).

72 Si no se tiene certeza sobre la protección de los tribunales, es el propio interesado el que debe protegerse, analizando e investigando minuciosamente a la contraparte antes de suscribir cualquier contrato. Entre los ámbitos más perjudicados están justamente las decisiones de largo plazo: las inversiones. Una empresa que piensa iniciar operaciones sabe que en el futuro enfrentará muchos conflictos y mientras más incierto ese panorama, más riesgosa será la decisión de involucrarse en el negocio.
} 
Con todo, las discusiones anteriores asumen que los jueces están interesados en la producción de precedentes, pero tal supuesto es una extensión natural del modelo de comportamiento judicial ${ }^{73}$, tema que no es materia de este trabajo.

Así las cosas, la falta de jurisprudencia y el no uso de precedentes en nuestro país nos privan de los beneficios antes señalados. De acuerdo a la legislación chilena, las sentencias judiciales solo son aplicables al caso específico que resuelven; más allá no tienen fuerza obligatoria: el artículo tercero del Código Civil es contundente ${ }^{74}$. Sin embargo, la doctrina y la propia realidad ha reconocido el valor interpretativo que se deriva de las resoluciones de los tribunales, en el sentido de que una decisión judicial contribuye a esclarecer el sentido de las normas. De esta manera, al decidir sobre un caso específico, los jueces orientan a los particulares sobre la forma en que deben entenderse y especialmente cumplirse las leyes.

Una de las maneras en que se puede enfrentar la falta de jurisprudencia en Chile es revisando el rol actual de la Corte Suprema, de forma que únicamente conozca los recursos más importantes del sistema, lo que le permitiría establecer criterios uniformes en relación con los problemas de mayor relevancia social, orientándose a una interpretación uniformadora del derecho y establecedora de jurisprudencia cognoscible y fundamentada. Para este efecto, resulta interesante estudiar la posibilidad de consagrar consti-

73 Un precedente proyecta la influencia de un juez con mayor eficiencia que una decisión que no tendrá ningún efecto para guiar el comportamiento futuro. Esto también explica por qué los jueces siguen y forman precedentes y, por tanto, por qué los abogados argumentan con base en el precedente. Si la generación de jueces actuales no sigue el precedente, la generación siguiente tenderá menos a seguir los precedentes de la generación actual, porque es menos probable que los jueces de la generación siguiente sean criticados por no seguir los precedentes de quienes los antecedieron. Para los jueces, los costos de la crítica profesional son modestos, pero, dado que las reglas de la antigüedad y la compensación judiciales atenúan los incentivos habituales que influyen en la gente, es probable que los jueces se vean afectados por lo que en la mayoría de los campos es una fuerza débil (la crítica). Es cierto que aquí hay un problema de "sombrero". El juez que se desentiende de un precedente deseando establecer el propio, contrario al precedente, podría minar de manera poco significativa la práctica de la decisión de acuerdo con el precedente; los costos privados de su acto pueden ser menores que las ganancias privadas. Sin embargo, la estructura de la revisión de apelación mantiene bajo control el problema del "sombrero". El juez que se desentiende de un precedente se verá refutado por un tribunal superior que no tiene interés en permitir que él mine la práctica de la decisión de acuerdo con el precedente a fin de magnificar su propia influencia. En cada jurisdicción hay un tribunal superior cuyas decisiones no están sujetas a nueva revisión. Y dentro de cada tribunal disminuye el problema del "sombrero". Si los magistrados de la Corte Suprema se desentienden del precedente en sus decisiones, saben que hacen disminuir la probabilidad de que los magistrados futuros respeten sus propias decisiones como precedente. Otro factor que impulsa a los jueces a seguir el precedente es el impacto del rechazo del precedente sobre la cantidad de litigios. Esta aumentará debido a la reducción de la certeza legal y generará una presión para que se añadan nuevos jueces (diluyendo así la influencia de los jueces existentes), se haga que cada juez trabaje más o se sustituyan los tribunales judiciales por tribunales arbitrales y administrativos, lo que reduciría el Poder Judicial. POSNER (2000) pp. 508-9. El análisis económico del comportamiento judicial es desarrollado en profundidad en POSNER (1993).

${ }^{74}$ El artículo $3^{\circ}$ del Código Civil señala:

"Solo toca al legislador explicar o interpretar la ley de un modo generalmente obligatorio.

Las sentencias judiciales no tienen fuerza obligatoria sino respecto de las causas en que actualmente se pronunciaren". 
tucionalmente la vinculatoriedad del precedente judicial emanado de los fallos de la Corte Suprema ${ }^{75}$, modificando parcialmente el actual artículo tercero del Código Civil y las normas sobre interpretación de la ley. Adicionalmente, se debe fortalecer y ampliar la actual norma vigente respecto de los recursos de casación con fallos contradictorios, facultando a las partes para detonar la intervención del pleno. Esto impondrá la obligación del respeto al precedente jurisdiccional de la propia Corte en materias jurídicas esenciales, tanto por esta misma como por todos los demás tribunales inferiores, y reportará crecientes grados de certidumbre y predictibilidad, que la sociedad está demandando del Poder Judicial.

\subsection{GESTIÓN, TRANSPARENCIA Y ACCOUNTABILITY JUDICIAL}

\subsubsection{Gestión y la cuestión del "aumento de los recursos"}

En la actualidad, la función administrativa de los tribunales es realizada en buena medida por ellos mismos, aunque existe unanimidad en que sería deseable contar con mecanismos que permitan al juez y a los funcionarios que lo asisten concentrarse en sus tareas jurisdiccionales, dejando aquella en manos de un órgano especializado. La Reforma Procesal Penal no solo está consiguiendo este objetivo con éxito, sino que ha logrado aumentar la eficiencia en el sistema.

Desgraciadamente, como resultado de esta desviación de funciones que vemos en la actualidad, tanto el juez como el secretario del tribunal deben destinar parte de su jornada a tareas administrativas, dificultando la "inmediación" del juez con la prueba, el proceso y las partes, dejando en manos de funcionarios subalternos la conducción del proceso y la redacción de resoluciones. Así las cosas, y adentrados ya en el siglo XXI con toda su lógica de división de funciones, se hace necesario entregar la administración de los tribunales a profesionales expertos en la materia, que permitan a los jueces concentrarse en su labor propia. Ello permitiría, a su vez, establecer criterios de eficiencia, índices de gestión públicos, evaluaciones periódicas, uso de sistemas informáticos y tecnologías de última generación, modernización de la cultura organizacional interna, aprovechamiento de las economías de escala de las organizaciones, entre otros. En esta materia, entre las reformas exitosas promovidas en el derecho comparado se encuentra la importancia de la reforma del despacho judicial, donde la evidencia muestra que los sistemas en que cada juez trabaja con arreglo a un calendario individual han tenido cierto éxito ${ }^{76}$.

\footnotetext{
75 Los conceptos establecidos en una causa anterior son aplicados para decidir nuevas causas en las que concurren hechos similares y traen a colación puntos similares de derecho; el juez puede desestimar el precedente, si una de las partes lo convence de que las características del caso hacen inaplicable la jurisprudencia existente; los tribunales inferiores deben acoger las decisiones de los superiores.

${ }^{76}$ En esos sistemas, un solo juez se encarga de un asunto de principio a fin. En el caso contrario, el del calendario maestro, el tribunal puede asignar diferentes partes de un asunto a diferentes jueces. Este segundo modelo tiene ciertas ventajas: el asunto se puede seguir tramitando si el juez se enferma o si tiene un gran número de casos por resolver, y los jueces se pueden especializar en las actuaciones procesales que
} 
Una cuestión estrechamente vinculada con las anteriores dice relación con la demanda de aumentos de recursos. En forma permanente, y tanto a nivel de los tribunales superiores de justicia como de los funcionarios judiciales se esgrime la falta de recursos y de personal como el principal factor que limita la eficiencia. Esto, por supuesto es una demanda permanente del resto de los órganos del Estado. La experiencia internacional en esta materia indica que el aumento de recursos por si solo no es una buena alternativa ${ }^{77}$. Además, muchas veces las medidas dirigidas a mejorar la eficiencia consisten en un aumento de los fondos junto con otras iniciativas, lo que hace difícil determinar cual es el efecto del aumento de los recursos en relación con otros factores ${ }^{78}$. En este sentido, parece ser que el aumento de los fondos contribuye a aliviar los retrasos pasajeros en los sistemas que se han esforzado seriamente por funcionar mejor, pero no dan gran resultado cuando las ineficiencias son muchas ${ }^{79}$. Por otra parte, hay aumentos de recursos que si pueden ayudar a los jueces a mejorar la administración, pero esto se relaciona más bien con lo que se sostenía precedentemente: la necesidad de profesionalizar la administración de los tribunales ${ }^{80}$.

pertenecen a su esfera de conocimientos técnicos. Pero también tiene desventajas. Ningún juez está completamente familiarizado con el asunto, diferentes jueces pueden fallar en forma distinta respecto del mismo asunto y -cuando un juicio se prolonga por mucho tiempo en una jurisdicción con este tipo de calendario- es difícil saber quién es responsable. Algunos estudios han determinado que la existencia de un calendario individual reduce el tiempo que transcurre hasta que se pronuncia el fallo, porque el juez encargado no solo está más familiarizado con los asuntos de que se ocupa sino que también se siente más responsable. BANCO MUNDIAL: (n.39), p. 125.

77 Con todo, el Informe del Banco Mundial sostiene que aunque muchas veces los niveles globales de recursos no tienen relación directa con la deficiencia judicial, en los casos en que la falta de financiamiento es extrema, una inyección de recursos puede ser eficaz. BANCO MUNDIAL (2002). Por su parte, Buscaglia y Ulen, presentan evidencia relativa a Estados Unidos y a los países de América Latina y el Caribe que demuestran que no hay una correlación entre el nivel total de recursos y el lapso transcurrido hasta que se dicta sentencia. BUSCAGLia y UlEn (1997). Por otra parte ver BUSCAGLIA y DaKOlias, donde los recursos asignados a los funcionarios judiciales adquieren gran relieve. BUSCAGLIA y DAKOLIAS (1996).

${ }^{78}$ Dakolias, observó que en Paraguay se aumentó el número de jueces al mismo tiempo que se introdujeron procedimientos orales. DAKOLIAS (1996)

79 Para Buscaglia y Ulen, los programas intensivos que tienen por objeto reducir los retrasos mediante la inyección de grandes cantidades de recursos han dado buenos resultados a corto plazo, pero estos no se pueden mantener si se realizan cambios más profundos. La introducción de sistemas informáticos u otro tipo de mecanización en un sistema judicial, que con frecuencia es un componente importante de las medidas de reforma patrocinadas por el Banco Mundial, ha contribuido a reducir los retrasos y la corrupción en América Latina. BusCAGLIA y UlEN (1997). En este sentido, gran parte de la reducción de la corrupción que se obtiene con ese tipo de reforma se debe probablemente a que con los sistemas mecanizados aumenta la responsabilidad. Los inventarios computarizados de los juicios en tramitación son más exactos y más fáciles de manejar que los procedimientos registrados en papel a los que reemplazan, y más de una persona puede tener acceso a ellos, lo que hace mas difícil que se puedan manipular.

80 En efecto: "En muchos sistemas judiciales una de las principales ineficiencias es la labor de tipo administrativo que desempeñan los jueces, como firmar cheques de sueldos o hacer pedidos de suministros de oficina. La centralización de esa labor en una sola oficina, cuyos empleados tenían formación administrativa, aumento la eficiencia de los tribunales en Colombia y Perú”. (BANCO MUNDIAL, 2002, p. 129). 


\subsubsection{Sistemas de Información y estadisticas: Transparencia y accountability judicial}

La transparencia exige que los ciudadanos y las organizaciones de la sociedad civil tengan acceso a información relevante y comprensible sobre la actuación de los poderes públicos, de modo que pueda evaluarlos y, eventualmente, exigir responsabilidades. En este sentido, transparencia, accountability e información pasan a ser conceptos profundamente interrelacionados.

Con todo, si bien los principios que han orientado el debate en Chile sobre esta materia quedaron expuestos con claridad en el Informe de la Comisión Nacional de Ética Pública (1994) y en cuerpos legales posteriores, parecen no haber llegado con fuerza al Poder Judicial ${ }^{81}$. Este escenario se ve agravado por una cultura judicial que pareciera querer escaparse del escrutinio público, comportamiento que siendo extensivo a la mayoría de las instituciones públicas, cobra particular relevancia social dada la naturaleza de la función y las labores que le encomienda la sociedad desarrollar al Poder Judicial. Sin lugar a dudas, esta situación tiene un impacto relevante en la baja confianza que tiene la sociedad sobre el mismo como se analizó al comienzo de este documento ${ }^{82}$.

Para hacer frente a esta situación, es diversa la literatura que ha buscado promover, en los Poderes Judiciales, la adopción de un sistema de información que permita saber en cada momento su situación y evolución ${ }^{83}$. En efecto, las estadísticas y los indicadores judiciales forman parte de dicho sistema, y permiten tener una idea más precisa sobre el estado de funcionamiento del Poder Judicial, y desde ahí poder hacer los

\footnotetext{
81 En este sentido, el Informe sostiene que: "La probidad pública se aplica a la conducta de los agentes públicos, y se refiere a la integridad en el cumplimiento de las obligaciones y deberes propios y anexos a los cargos y funciones públicas (...) La integridad plantea fuertes exigencias en el recto cumplimiento de las normas que definen y regulan la actividad pública. Por esta razón, la integridad expresa la relación de la probidad hacia la conducta pública considerada en sí misma, y, por lo mismo, a su adecuación al código ético y jurídico que le sirve de fundamento (...) Sin embargo, en un régimen democrático, la integridad no es suficiente. En las democracias, la probidad se extiende a la responsabilidad, en su aceptación de obligación de agente público de responder por el desempeño de sus funciones ante la sociedad civil. La responsabilidad pública, en consecuencia, es la cualidad de aquel que da cuenta, ante quien corresponde, sobre el ejercicio de la función que le ha sido atribuida. De este modo, la responsabilidad es parte de la probidad, en relación a quien, en última instancia, está encargada de evaluarla y juzgarla: la ciudadanía (...) En las sociedades democráticas, esa evaluación requiere que las conductas y acciones, a través de las cuales se canalizan las funciones públicas, se realicen de tal modo que ellas estén siempre, salvo escasas excepciones, expuestas a la vista y el conocimiento de la sociedad civil. El carácter transparente de las funciones constituye un principio anexo a la integridad y la responsabilidad (...) En ausencia de disposiciones, mecanismos e instrumentos que hagan exigible la transparencia, la probidad pública no puede ser sometida al escrutinio ciudadano y, en consecuencia, su mera enunciación es letra muerta. La transparencia se aplica a la totalidad de la función pública. Incluye, en consecuencia, al agente, la gestión y los actos públicos. Es sabido que los fenómenos de corrupción proliferan cuando las funciones públicas no son transparentes y escapan, por lo mismo, al control institucional y ciudadano". (INFORME DE LA COMISIÓN NACIONAL DE ETICA PÚBLICA, 1994, pp. 6 y 7).

82 Ver nota 1.

83 Bibliografía relevante en esta materia se encuentra en los trabajos de PASTOR y MASPONS (2004); VERA institute of Justice (2003); NACIONAL CEnTER For State Courts (1995); y Gavarano (2000).
} 
diagnósticos y las propuestas de políticas y medidas que se deban implementar para enmendar rumbo ${ }^{84}$.

La experiencia internacional en materia de reforma judicial pone de relieve la necesidad del libre intercambio de información. Se ha observado que las reformas que introducen un mayor grado de accountability de los jueces ante los usuarios del sistema judicial y ante el público en general han contribuido más a mejorar la eficiencia que el simple aumento de los recursos financieros y humanos. En los países en desarrollo se puede lograr más accountability facilitando más información sobre el desempeño judicial. En muchos casos, los grupos influyentes de la sociedad civil y los medios de comunicación, actuando como observadores externos, han modificado el comportamiento de los jueces y los abogados. El establecimiento de bases de datos judiciales que faciliten el seguimiento de los procesos de y reduzca el riesgo de manipulación y traspapeleo, puede aumentar el accountability y, en consecuencia, la rapidez con la que se llega a una decisión ${ }^{85}$.

En este sentido, si se exige a los jueces que den cuenta de sus acciones, los sistemas judiciales serán más eficientes y los juicios se resolverán con más rapidez e imparcialidad. Los incentivos que se presentan a los jueces repercuten en su desempeño. El diseño institucional influye en dichos incentivos. Uno de los factores principales más influyentes es la información sobre el desempeño judicial, que permite que se vigile su actuación. Una alternativa utilizada con frecuencia es la imposición de plazos legales para la resolución de determinados tipos de asuntos. Esta solución se ha adoptado con frecuencia cuando los juicios se caracterizan por su lentitud, pero los resultados hasta la fecha no han sido muy alentadores ${ }^{86}$.

Otro de los elementos relevantes a tomar en consideración dice relación con el efecto que tiene el contar con estadísticas judiciales respecto de la reputación de los jueces, cuestión que en sociedades con medios de comunicación activos puede generar incentivos a que los jueces se preocupen más cuidadosamente de la forma en que ejercen su labor -en especial la forma de manejar el despacho judicial- y el producto que le entregan a la sociedad -junto a la correspondiente eficiencia en el proceso-. En este sentido, evidencia empírica en los años 80' muestra que en los programas destinados a reducir las demoras en Estados Unidos se observa que los problemas de un caso, como una demora excesiva, se pueden atribuir con precisión a un juez concreto, por lo que la

\footnotetext{
${ }^{84}$ En efecto, la adopción de sistemas de información no tan solo tiene valor desde el punto de vista del funcionamiento interno del Poder Judicial: son también valiosos desde el punto de vista externo en la medida que dan cuenta a la ciudadanía de la forma en que el Poder Judicial desempeña su labor. En este sentido, se debe partir de la base de que el Poder Judicial - al igual que los otros poderes del Estado- tiene que mostrarle y demostrarle a la sociedad, que está cumpliendo en forma eficaz y eficiente con el rol que se le ha encomendado. Eficaz, en el sentido de que está proveyendo los bienes públicos que se le pide que provea: paz social, certeza jurídica, jurisprudencia. Eficiente, en el sentido de que está aprovechando los recursos que se le entregan de la mejor manera posible (se debe considerar que los recursos destinados al Poder Judicial compiten con otras áreas prioritarias: educación, superación de la pobreza, salud, etc.).

85 BANCO MUNDiAL (2002) p. 118-9

${ }^{86}$ BANCO MUNDiAL (2002) p. 125
} 
existencia de calendarios individuales hace que los jueces trabajen con mas ahínco y administren los asuntos con mas eficacia ${ }^{87}$. Por otra parte, los efectos en la reputación son un factor decisivo respecto de los retrasos en los tribunales. Sin embargo, es difícil medir esa influencia. Algunas reformas, como la divulgación de estadísticas judiciales, son eficaces porque sirven de base para evaluar la eficiencia de los jueces y, por lo tanto, afectan a su reputación. Asimismo, evidencia empírica muestra que la transmisión por televisión de las actuaciones judiciales en el estado de Nueva York permitió establecer que ese tipo de escrutinio aumenta en un tercio la eficiencia de los jueces $y$, al mismo tiempo, mejora la calidad de sus fallos ${ }^{88}$. Con todo, este último tipo de procedimiento también ha recibido críticas ${ }^{89}$.

Finalmente, no se puede dejar de considerar que en el caso chileno, el control disciplinario de los integrantes del Poder Judicial recae en los superiores jerárquicos del propio sistema (así como las calificaciones y conformaciones de nóminas, ternas, etc.), lo que dificulta su independencia y capacidades, ya que, al final de cuentas, el sistema judicial se constituye en juez y parte de sí mismo ${ }^{90}$. Además, la responsabilidad y el tiempo que exigen estas funciones internas sin duda aleja a los jueces de su función principal: resolver los conflictos que los miembros de la sociedad no han podido resolver por sí mismos. Separar el control disciplinario de la labor jurisdiccional parece una propuesta interesante, sobre todo si se considera un ente funcionalmente autónomo, integrado por personas de reconocida integridad y ajenas a la carrera judicial.

\section{CONCLUSIONES}

Es imperioso que los actores más relevantes del sector justicia en particular, como asimismo el país en general, tomen conciencia sobre la necesidad de abocarse al estudio y diseño de una Reforma Procesal Civil. En este sentido, parece una buena señal la constitución en 2005 del Foro Procesal Civil, que convocado por el Ejecutivo, reúne a destacados académicos y expertos.

El actual esquema de justicia civil está agotado, y la evidencia empírica en esta materia así lo demuestra. La reforma en este sector, al igual como sucediera en materia penal, deberá significar una completa transformación de las estructuras la que en muchos ámbitos será radical. Llevará a introducir la racionalidad económica para entender la función del sector judicial y sus limitaciones, una revisión de las pautas organizacionales al interior de las instituciones que fueron objeto de modificaciones, la implemen-

\footnotetext{
87 NeUBAUER et al. (1981)

88 BANCO MUNDiAL (2002)

${ }^{89}$ A modo de ejemplo ver Valledecabres OrTiz (2004)

${ }^{90} \mathrm{La}$ independencia judicial consiste en que las autoridades de otros poderes no interfieran en las decisiones de los jueces, pero el principio completo supone que nadie lo haga: tampoco las autoridades judiciales, excepto en el riguroso marco de los recursos propiamente jurisdiccionales. Sin este concepto de independencia entendido en un sentido más amplio, es imposible hablar de imparcialidad, y sin imparcialidad el concepto mismo de juez carece de sentido.
} 
tación de sistemas informáticos, indicadores de gestión, y por cierto, un nuevo esquema oral en lo procesal.

En el espíritu anterior es que este documento ha buscado analizar algunos de los elementos centrales que deben considerarse de cara a una reforma a la justicia civil, proponiendo lineamientos y medidas de carácter general que puedan ser discutidas en el futuro. En primer lugar, debe pensarse en un nuevo esquema que permita a los jueces abocarse a realizar su tarea primordial, la resolución de conflictos jurídicos, y no a realizar tareas de otro orden como la ejecución de cobranzas, el conocimiento de asuntos no contenciosos y distintas funciones de orden administrativo; en segundo lugar, se debe revisar la institucionalidad general de resolución de conflictos, que se caracteriza por el excesivo protagonismo que entrega al Poder Judicial, en desmedro de otros mecanismos públicos y privados de resolución de conflictos (alternativos); en tercer lugar, existe una serie de reformas funcionales y procedimentales en las que existe bastante consenso para avanzar, pudiendo servir para ello las instituciones y experiencias del derecho comparado, o algunos modelos ya incorporados en los nuevos procedimientos de familia y laboral, serán de gran utilidad, resolviendo muchos tópicos en forma acertada, considerando además, que la simplificación de procedimientos puede tener un impacto positivo en materia de eficiencia judicial y prevención de la corrupción; en cuarto lugar, y considerando la implementación de las reformas precedentes, debiera esperarse una mejora sustancial en la calidad de las sentencias, aumentando con ellas la certeza jurídica al interior de la sociedad, lo que sumado a reformas que reforzarán o generarán un sistema de precedentes judiciales, mejoraría notablemente la calidad de nuestro derecho e instituciones jurídicas; y, finalmente, se debe optimizar la gestión de los recursos la justicia civil, lo que está vinculado a reformas en gestión y al uso de sistemas de información, lo que a su vez importa elevar los estándares de transparencia y accountability judicial, tan criticados en la actualidad y que podrían tener un impacto positivo en la confianza de las personas.

Todo lo antes mencionado debe ir acompañado en forma paralela, de un profundo proceso de modernización de la red auxiliar de administración de justicia (notarios, conservadores, receptores, etc.), proceso sin el cual el complejo andamiaje de la justicia civil seguiría moviéndose a media máquina en su día a día.

Por otra parte, se debe ser extremadamente cuidadoso en el análisis como asimismo prudente en la "importación" así sin más de las instituciones y figuras jurídicas del derecho comparado. Esto es válido tanto respecto de aquellas instituciones que han demostrado ser eficientes y eficaces cuando han sido importadas por otros países (especialmente si son países que tienen un sistema jurídico de otra naturaleza), como por las diversas dimensiones que se deben considerar al momento del análisis. Así, "medir el éxito" de los diversos procedimientos (desde una perspectiva comparada) en términos de justicia es una decisión compleja. No es suficiente el preguntarse si acaso el sistema produce decisiones correctas. También debemos preguntar por la dimensión temporal de las sentencias, porque una sentencia tardía podría importar más bien una denegación de justicia incluso aunque la decisión haya sido correcta desde el punto de vista de la aplicación de la ley a los hechos del caso. Los costos también son relevantes a la hora de evaluar los sistemas procesales. Los recursos disponibles al sistema influirán en el nivel 
global de rectitud de las decisiones. Los costos afectaran el acceso a la justicia y, finalmente, altos costos pueden generar que los litigantes más ricos adquieran una ventaja procesal contra sus oponentes. De lo anterior se sigue que cuando miramos diferentes sistemas, no debemos solamente comparar cómo aspectos particulares del procedimiento son tratados por estos. Dicha comparación es de poca utilidad. Por ejemplo, el discovery obligatorio de documentos es una figura central de los sistemas anglo-americanos, pero ausente de los sistemas continentales de código (en los países con instituciones más modernas, la cercanía de la primera audiencia o audiencia de prueba, provee una solución similar en sus efectos).

La Reforma a la Justicia Civil aparece hoy en día como prioritaria en la agenda de políticas públicas, más aún cuando está en el corazón de los conflictos jurídicos que viven los chilenos en su vida cotidiana. Las propuestas aquí analizadas tienen por objeto contribuir a este debate naciente, y por lo mismo, no pueden entenderse como rígidas o definitivas. El proceso de reforma recién comienza, por lo que es de gran importancia que tanto las autoridades públicas como el mundo académico generen los espacios para empezar a establecer los consensos que definan los lineamientos y tiempos de una reforma indispensable.

\section{BIBLIOGRAFÍA}

BAird, Douglas, Picker, Randal y GerTner, Robert (1994): Game Theory and the Law (Boston, Harvard University Press) 330 pp.

Banco Mundial (2002): Informe sobre el Desarrollo Mundial 2002: Instituciones para los Mercados (Washington D.C., Mundi-Prensa) 249 pp.

BECK, Thorsten y LeVINE, Ross (2003): "Legal Institutions and Financial Development", NBER Working Paper No. 10126. (National Bureau of Economic Research, Massachusetts), $42 \mathrm{pp}$. [consulta: 10 de marzo de 2006]. Disponible en línea en <http://www.nber.org/papers/w10126>

Bundy, Stephen y ElHauge, Einer (1991): "Do Lawyers Improve the Adversary System? A General Theory of Litigation Advice and Its Regulation", en: California Law Review, Vol. 79, pp. 313-420.

BusCaglia, Edgardo (1997): "Los principales obstáculos de la Reforma Judicial en América Latina" en: JARQUIN, Edmundo y CARRILlo, Fernando: La Economía Politica de la Reforma Judicial (Washington D.C., BID) 476 pp.

BusCaglia, Edgardo y UlEn, Thomas (1997): "A Quantitative Assessment of the Efficiency of the Judicial Sector in Latin America", en: International Review of Law and Economics, Vol. 17.

BusCAGLiA, Edgardo y Dakolias, María (1996): "Judicial Reform in Latin American Courts: The experience in Argentina and Ecuador", en: World Bank Technical Paper No. 350 (Washington D.C., Banco Mundial) 68 pp.

Centro de Estudios Públicos (diciembre 2002), Estudio Nacional de Opinión Pública (CEP, Santiago). [consulta: 10 de marzo de 2006]. Disponible en línea en <http:// www.cepchile.cl> 
Centro de Estudios de la Realidad Contemporánea (agosto 2005), Informe de Prensa Encuesta Nacional. [consulta: 10 de marzo de 2006] Disponible en línea en $<$ http://www.cerc.cl/Encuestas/05AGOS.pdf>

Cerda, Carlos (1992): Duración del Procedimiento Civil Ordinario en los Juzgados de Santiago (Santiago, FONDECYT), 115 pp.

CoOter, Robert y Ullen, Thomas (1988): Derecho y Economía (México D.F., Fondo de Cultura Económica) 686 pp.

Cooter, Robert y Rubinfield, Daniel (1989): “Economic Analysis of Legal Disputes and Their Resolution", en: Journal of Economic Literature, Vol. 27, pp. 1067-1097.

Corporación Participa (2004): Estudio de Acceso a la Información Pública. [consulta: 10 de marzo de 2006]. Disponible en línea en http://www.participa.cl

DAKOlias, Maria (1996): "The Judicial Sector in Latin America and the Caribbean: Elements of Reform”, en: World Bank Technical Paper No. 319 (Washington D.C., Banco Mundial). 102 pp.

DAM, Kenneth (2006a): "Institutions, History and Economic Development", en: The University of Chicago Law and Economics Working Papers, No. 271. (Chicago, The University of Chicago) $29 \mathrm{pp}$.

DAM, Kenneth (2006b): "Credit Markets, Creditors' Rights and Economic Development", en: The University of Chicago Law and Economics Working Papers, No. 281. (Chicago, The University of Chicago) $36 \mathrm{pp}$.

DAM, Kenneth (2006c): "The Judiciary and Economic Development", en: The University of Chicago Law and Economics Working Papers, No. 287. (Chicago, The University of Chicago) $41 \mathrm{pp}$.

DwORKIn, Ronald (1985): A Matter of Principle (Boston, Harvard University Press) $448 \mathrm{pp}$.

GaVARANO, Germán (2000): Indicadores de desempeño judicial (Buenos Aires, FORES). [consulta: 10 de marzo de 2006] Disponible en línea en <http:// www.foresjusticia.org.ar>

HUA, Xinyu y SPIER, Kathryn (2004): "Information and Externalities in sequential litigation", en: NBER Working Paper No. 10943. (Massachusetts, National Bureau of Economic Research). 31 pp.

Informe de la Comisión Nacional de Ética Pública (1994): Ética Pública: Probidad, Transparencia y Responsabilidad al servicio de los Ciudadanos (Santiago, Gobierno de Chile) 76 pp.

Jarquin, Edmundo y CARrillo, Fernando (1997): La Economía Politica de la Reforma Judicial (Washington D.C., BID) 476 pp.

KAPLOW, Louis y SHAVELl, Steven (1989): "Legal Advice about Information to Present in Litigation: Its effects and Social Desirability", en: Harvard Law Review, Vol. 102, pp. 565-615.

LANDES, William (1971): “An Economic Analysis of the Courts", en: Journal of Law and Economics, Vol. 14, pp. 61-107

Landes, William y Posner, Richard (1976): "Legal Precedent: A Theoretical and Empirical Analysis", en: Journal of Law and Economics, Vol. 19, pp. 249-307 
La Porta, Rafael, Lopez de Silanes, Florencio, Schleifer, Andrei, Vishny, Robert (1998): "Law and Finance", en: Journal of Political Economy Vol. 16, 1998, pp. 11131155

La Porta, Rafael, Lopez de Silanes, Florencio, SChleifer, Andrei, Vishny, Robert (2003): "Judicial Checks and Balances", en: Journal of Political Economy, Vol. 112 (2). (Massachussets, National Bureau of Economic Research). pp. 445-470.

LaRroulet, Cristián y MOCHON, Francisco (2003): Economía (Madrid, Mc Graw Hill) $2^{\mathrm{a}}$ ed. $662 \mathrm{pp}$.

Latinobarómetro (2003): Encuestas en Series de Tiempo. [consulta: 10 de marzo de 2006]. Disponible en http://www.latinobarometro.org

Libertad y Desarrollo (2005): "Encuesta de Corrupción 2005: Percepción y Realidad”, Serie Informe Politico No. 90. (Santiago, Libertad y Desarrollo), 34 pp.

Mahoney, Paul (2001): "The Common Law and Economic Growth: Hayek Might Be Right", en: Journal of Legal Studies, Vol. 30, pp. 503-525

MERY, Rafael (2003): "Una aproximación teórica y empírica a la litigación civil en Chile", en: Documento de Trabajo No. 7 CEDIEM (Santiago, Universidad Diego Portales). 45 pp.

National Center for State Courts (1995): Trial Court Performance Standards National Center for State Courts). [consulta: 10 de marzo de 2006]. Disponible en línea y en su versión 2003 en <http://www.ncsconline.org>

Neubauer, David (1981): Managing the Pace of Justice: An Evaluation of LEAA's Court Delay-Reduction Programs (Washington D.C., National Institute of Justice-U.S. Department of Justice) 439 pp.

NORTH, Douglas (1981): Structure and Change in Economic History (New York, Norton) $240 \mathrm{pp}$.

NORTH, Douglas (1990): Institutions, Institutional Change and Economic Performance (Cambridge, Cambridge University Press) 159 pp.

NorTOn, Seth (1998): "Poverty, Property Rights and Human Well-Being: A Cross National Study", Cato Journal Vol. 18, No. 2, (Washington D.C., CATO INSTITUTE) pp. 233-245.

PASARA, Luis (1997): "La Reforma Judicial y la Sociedad Civil” en: JARQUIN, Edmundo y CARrillo, Fernando: La Economía Politica de la Reforma Judicial (Washington D.C., BID) 476 pp.

PASTOR, Santos (1997): “QQué es la Reforma Judicial y qué cabe esperar de ella?” en: Jarquin, Edmundo y Carrillo, Fernando, La Economía Política de la Reforma Judicial (Washington D.C., BID) 476 pp.

PASTOR, Santos y MASPONS, Liliana (2004): Manual Cifrar y Descifrar o Indicadores Judiciales para las Américas (Santiago, CEJA). 84 pp.

PEÑA, Carlos (1994): Sobre la necesidad de las formas alternativas de resolución de conflictos (Santiago, Corporación de Promoción Universitaria), 178 pp.

PeÑA, Carlos (1999): “'A qué nos obliga la democracia? Notas para el debate sobre la reforma judicial” en PeÑa, Carlos; Verdugo, Mario; RamíreZ, José; Correa, Jorge; BATES, Luis y CORTÉS, "El Poder Judicial en la Encrucijada: Estudios acerca de la 
Política Judicial en Chile". Cuadernos de Análisis Jurídico No 22 (Santiago, Universidad Diego Portales), 264 pp.

POLINSKY, Mitchell (2003): An Introduction to Law and Economics (New York, Aspen) $181 \mathrm{pp}$.

POLINSKY, Mitchell y SHAVELL, Steven (1989): "Legal Error, Litigation, and the Incentive to Obey the Law", en: Journal of Law, Economics and Organization, Vol. 5, pp. 99108.

Posner, Richard (1973): "An Economic Approach to Legal Procedure and Judicial Administration", en: Journal of Legal Studies, Vol. 2, pp. 399-458

POSNER, Richard (1981): The Economics of Justice (Boston, Harvard University Press) 415 pp.

Posner, Richard (1993): "What Do Judges and Justices Maximize? (The Same Thing Everybody Else Does), en: Supreme Court Economic Review, Vol. 3, pp. 1-41

POSNER, Richard (2000): El análisis económico del derecho (Ciudad de México, Fondo de Cultura Económica) 682 pp.

SAMUELSON, Paul (1954): "The pure theory of public expenditure", en: Review of Economics and Statistics, Vol. 36, pp. 387-389.

SHAVEll, Steven (1982): "Suit, Settlement and Trial: A Theoretical Analysis Under Alternative Methods for the Allocation of Legal Costs", en: Journal of Legal Studies, Vol. 11, pp. 55-81.

ShaVELL, Steven (2003): "Economic Analysis of Litigation and Legal Process", en: NBER Working Paper No. 9697 (Massachusetts, National Bureau of Economic Research) $66 \mathrm{pp}$.

SHAVELL, Steven (2004a): Foundations of Economic Analysis of Law (Boston, Harvard University Press) 737 pp.

SHAVELL, Steven (2004b): Economic Analysis of Law (New York, Foundation Press) 121 pp.

SHERwOOD, Robert, Sheperd, Geoffrey, De Souza, Celso (1994): "Judicial Systems and Economic Performance", en: Quarterly Review of Economics and Finance, Vol. 34, pp. $101-116$

SHERWOOD, Robert (1997): "Sistema Judicial y Desarrollo Económico" en: JARQUIN, Edmundo y Carrillo, Fernando: La Economía Politica de la Reforma Judicial (Washington D.C., BID) 476 pp.

Silva BASCUŃÁn, Alejandro (1997): Tratado de Derecho Constitucional, Tomo I (Santiago, Editorial Jurídica) 588 pp.

Universidad Diego Portales (2004): Barómetro de Acceso a la Información Pública. [consulta: 10 de marzo de 2006]. Disponible en línea en: <http://www.udp. cl/ icso/investigacion/doc/barometroinforme.pdf>

VAlledecabres OrTiz, María Isabel (2004): "Imparcialidad del juez y medios de comunicación" (Valencia, Editorial Tirant lo Blanch) 768 pp.

VARGas, Juan Enrique, PeÑA, Carlos y CORREA, Jorge (2001): "El Rol del Estado y el Mercado en la Justicia", Cuadernos de Análisis Jurídico $N^{\circ} 42$ (Santiago, Universidad Diego Portales) 200 pp. 
García, José Francisco y Leturia, Francisco Javier — "Justicia Civil: Diagnóstico, evidencia empírica..."

VARGAS, Juan Enrique (2005): "Financiamiento Privado de la Justicia: Tasas Judiciales", en: Sistemas Judiciales $N^{\circ}$ 9: Abogacía y Educación Legal (Santiago, Centro de Estudios de Justicia de las Américas) 167 pp.

Vera Institute of JUSTICE (2003): Measuring Progress toward Safety and Justice: A Global Guide to the design of Performance Indicators across the Justice Sector (New York, Vera InSTITUTE of Justice [consulta: 10 de marzo de 2006]. Disponible en línea en http://www.vera.org/indicators

Zuckerman, Adrian (1999): Civil Justice in Crisis: Comparative Perspectives of Civil Procedure, (Oxford, Oxford University Press) 485 pp. 